\title{
2016 updated EULAR evidence-based recommendations for the management of gout
}

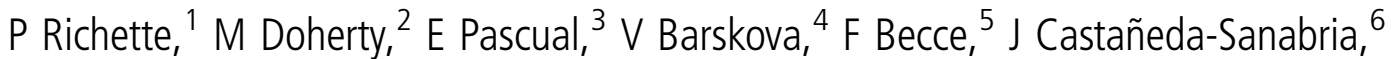

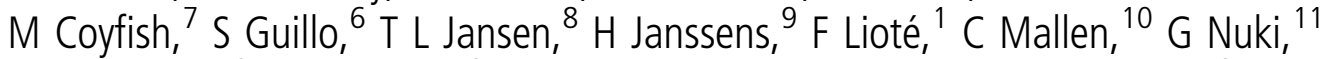

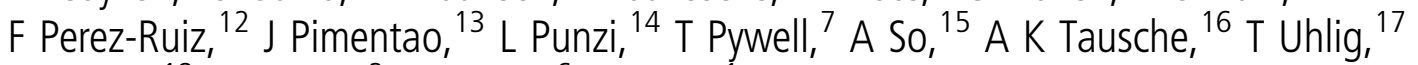 \\ J Zavada, ${ }^{18}$ W Zhang, ${ }^{2}$ F Tubach, ${ }^{6}{\text { T } \text { Bardin }^{1}}^{1}$
}

- Additional material is published online only. To view please visit the journal online (http://dx.doi.org/10.1136/ annrheumdis-2016-209707).

For numbered affiliations see end of article.

\section{Correspondence to} Professor Pascal Richette, Fédération de Rhumatologie, Centre Viggo Petersen, Hôpita Lariboisière, 2 rue Ambroise Paré, Paris 75010, France; pascal.richette@aphp.fr

Received 13 April 2016 Revised 14 June 2016 Accepted 29 June 2016 Published Online First 25 July 2016

\section{ABSTRACT}

Background New drugs and new evidence concerning the use of established treatments have become available since the publication of the first European League Against Rheumatism (EULAR) recommendations for the management of gout, in 2006. This situation has prompted a systematic review and update of the 2006 recommendations.

Methods The EULAR task force consisted of 15 rheumatologists, 1 radiologist, 2 general practitioners, 1 research fellow, 2 patients and 3 experts in epidemiology/methodology from 12 European countries. A systematic review of the literature concerning all aspects of gout treatments was performed.

Subsequently, recommendations were formulated by use of a Delphi consensus approach.

Results Three overarching principles and 11 key recommendations were generated. For the treatment of flare, colchicine, non-steroidal anti-inflammatory drugs (NSAIDs), oral or intra-articular steroids or a combination are recommended. In patients with frequent flare and contraindications to colchicine, NSAIDs and corticosteroids, an interleukin-1 blocker should be considered. In addition to education and a nonpharmacological management approach, urate-lowering therapy (ULT) should be considered from the first presentation of the disease, and serum uric acid (SUA) levels should be maintained at $<6 \mathrm{mg} / \mathrm{dL}(360 \mu \mathrm{mol} / \mathrm{L})$ and $<5 \mathrm{mg} / \mathrm{dL}(300 \mu \mathrm{mol} / \mathrm{L})$ in those with severe gout. Allopurinol is recommended as first-line ULT and its dosage should be adjusted according to renal function. If the SUA target cannot be achieved with allopurinol, then febuxostat, a uricosuric or combining a xanthine oxidase inhibitor with a uricosuric should be considered. For patients with refractory gout, pegloticase is recommended.

Conclusions These recommendations aim to inform physicians and patients about the non-pharmacological and pharmacological treatments for gout and to provide the best strategies to achieve the predefined urate target to cure the disease.

\section{INTRODUCTION}

CrossMark

To cite: Richette $P$,

Doherty M, Pascual E, et al. Ann Rheum Dis

2017;76:29-42
Gout is a disabling and common disease in Europe; its prevalence ranges from $0.9 \%$ to $2.5 \%$ depending on the country. ${ }^{1-3}$ The prevalence and incidence of the disease have increased steadily in recent years, particularly in the UK. ${ }^{4}{ }^{5}$ However, despite effective treatments, gout is still often misdiagnosed and its management remains suboptimal. $^{3} 67$ This situation prompted the elaboration of the first European League Against Rheumatism (EULAR) recommendations for the management of gout, in 2006, which were based on a systematic literature review (SLR) and expert opinion. $^{8}$

Since 2006, our knowledge of the pathophysiology of the disease has improved greatly ${ }^{9} 10$ and the field of gout management has advanced quickly. When the first EULAR recommendations were produced, the number of drugs available for gout treatment was limited and the main uratelowering therapy (ULT) was allopurinol. Since then, a number of new drugs have become available or are in late-stage development (ie, febuxostat, pegloticase, interleukin-1 (IL-1) blockers, lesinurad). ${ }^{11}$ Moreover, additional data on established drugs such as colchicine ${ }^{13}$ and allopurinol ${ }^{14-}$ 16 have been published, and studies have repeatedly identified increased cardiovascular mortality with gout. $^{17}$

Therefore, the indications for old and new drugs need to be clarified and novel therapeutic strategies recommended on the basis of their availability, the patient profile, previous drug failure and benefit/ risk ratio as well as the cost of the various drugs now available for the treatment of flare and for lowering urate levels. For this purpose, a task force was convened to update the 2006 EULAR recommendations for the management of gout, with the objective of addressing all overarching principles and individual recommendations by a SLR and expert and patient opinion.

\section{METHODS}

With the approval of the EULAR executive committee, the convenor (TB) along with two co-convenors of the 2006 task force (MD and EP), an epidemiologist (FT) and an academic rheumatologist (PR) formed a steering group to update the 2006 EULAR recommendations for the management of gout. The steering group prioritised the research questions, drafted the methodology to be used for these novel set of recommendations and assembled a task force.

This EULAR task force comprised 15 rheumatologists, 1 musculoskeletal radiologist, 2 general practitioners (GPs), 1 research fellow, 2 patients and 3 experts in epidemiology/methodology from 12 European countries. The recommendations were developed according to the standardised operating procedures for the elaboration, evaluation 
dissemination and implementation of recommendations endorsed by the EULAR. ${ }^{18} 19$

The first step was to determine whether the 12 former EULAR recommendations (2006) for the management of gout should be retained, modified or abandoned. For this purpose, members of the task force were sent a questionnaire and were asked to rate each recommendation by using a 9-point numerical rating scale (1, totally disagree; 9, fully agree). For each item, participants indicated whether they would keep the same recommendation (first question). If the answer was scored $\geq 5$, the participants were then asked if they would modify the recommendation (second question). It was explained that the phrasing of the updated recommendations should not be a mere clinical statement-as for most of the 2006 EULAR recommendations-but wherever possible should take the form of a clear active recommendation specific to a particular clinical situation, as advised by the Appraisal of Guidelines for Research \& Evaluation (AGREE II). ${ }^{20}$ The steering group had predetermined that an item from the 2006 recommendations would be deleted if all scores from the participants for the first question were $<5$ with a median $\leq 3.5$. Conversely, the item would be unchanged if all scores for to the first question were $\geq 5$ with a median $\geq 7$ and when all scores for the second question were $<5$ with a median $\leq 3.5$. If not, the items had to be modified. Members of the task force were also invited to indicate topics they would like to address for additional recommendations.

Subsequently, one research fellow (JC-S) with the help of an expert in systematic review methodology (SG) performed an SLR by searching for literature published since 1 January 2005 in MEDLINE, EMBASE and Cochrane Library databases in June 2013. This process included both a general search and a proposition-specific search. The general search strategy consisted of two basic components: (1) gout in whatever possible terms in the databases and (2) types of study design in the forms of systematic review/meta-analysis, randomised controlled trial (RCT)/controlled trial, uncontrolled trial, cohort study, casecontrol study, cross-sectional study. The two components were combined to search for the current available research evidence on gout. The quality of evidence and grades of recommendation were determined according to the standards of the Oxford Centre for Evidence-Based Medicine. ${ }^{19}$ The quality of evidence was assessed by the GRADE method. Criteria for RCTs included adequate randomisation and allocation concealment, prognostic similarity between groups (in terms of the evaluated outcome), equal follow-up of groups, adequate blinding, validation of outcomes, application of intent-to-treat analysis, selective outcome reporting, stopping early for benefit, $\alpha$-risk control with multiple comparisons or multiple outcomes. Criteria for observational studies included choice of controls, measurement of both exposures and outcomes, confounding factors, completeness of data, magnitude of effect and dose-response gradient. Criteria for meta-analysis included a priori-defined objectives and outcomes of interest, description of the literature search, selection criteria for included studies, assessment of quality of studies, evaluation of publication bias and homogeneity of results.

In the next step, all task force members attended a 2-day meeting during which results of the SLR were presented in an aggregated form. The task force debated and evaluated the evidence presented and formulated a preliminary set of new recommendations. Then, the task force reached consensus regarding the proposed recommendations by using the Delphi sequential voting technique by email after the meeting. Subsequently, the level of agreement for each recommendation was graded. Each participant was asked to rate each recommendation again by using the 9-point numerical rating scale (1, totally disagree; 9 , fully agree) and could propose a reformulation of the recommendation.

Subsequently, this set of recommendations was externally evaluated by GPs $(n=8)$ and rheumatologists $(n=5)$ mainly in independent or private practice in Europe (the UK, The Netherlands, Spain, France, Portugal and Italy). Each physician was asked to rate each recommendation by using the abovementioned numerical rating scale. Finally, the task force set up a research agenda to discuss and develop 14 proposals.

Finally, because the delay between the first SLR and the writing of the present manuscript was longer than expected, we conducted an additional SLR from June 2013 to May 2016. Results from this updated SLR can be found in the online supplementary material. The steering group discussed result of this SLR and agreed that it did not impact the overall content of the whole recommendations. Relevant references have been inserted in the body of the manuscript.

\section{RESULTS}

The task force voted unanimously for a change in all items of the 2006 recommendations (see online supplementary material). Therefore, all the previous recommendations were amended to reflect newly available evidence from the SLR. In total, 984 references were retrieved form the literature search, among which 51 were analysed (see flow chart, online supplementary material).

At the end of the 2-day meeting, a set of 14 preliminary new recommendations was produced and three Delphi rounds by email were needed to establish the final set of recommendations. Because too many recommendations might result in a loss of focus, the steering committee decided to move the first three recommendations under the umbrella of 'overarching principles', for a final set of 11 novel recommendations that focus more specifically on the treatment of flares and long-term management (tables 1 and 2). The external evaluation is provided as online supplementary material, and the research agenda appears in box 1 .

\section{Overarching principles}

A. Every person with gout should be fully informed about the pathophysiology of the disease, the existence of effective treatments, associated comorbidities and the principles of managing acute attacks and eliminating urate crystals through lifelong lowering of SUA below a target level.

Although gout is a curable disease, its management is still not optimal in a large proportion of patients. ${ }^{6}$ Recent studies report that less than half of the patients with gout receive ULT, and that when prescribed, it is often at an insufficient dose to effectively lower the SUA levels to target. ${ }^{21-24}$ Since the last 2006 recommendations, barriers to the effective treatment and cure of gout have been identified and the importance of the lack of knowledge of the disease and subsequent non-adherence to treatment have been emphasised. ${ }^{25-27}$ Moreover, an observational study showed that full patient education increased adherence to ULT, leading to a high rate (92\%) of effectively treated patients at 12 months. ${ }^{28}$

Education of patients was mentioned in the 2006 recommendation (item 2) together with general advice regarding lifestyle as part of a global recommendation. With this first overarching principle dedicated solely to education, the task force emphasises that education is a key aspect of gout management. Also it introduces the approach 'treat to serum urate target,' which has been found effective in alleviating all features of the disease. ${ }^{28}$ 


\section{Table 1 Overarching principles and final set of 11 recommendations for the treatment of gout}

\section{Overarching principles}

A Every person with gout should be fully informed about the pathophysiology of the disease, the existence of effective treatments, associated comorbidities and the principles of managing acute attacks and eliminating urate crystals through lifelong lowering of SUA level below a target level.

B Every person with gout should receive advice regarding lifestyle: weight loss if appropriate and avoidance of alcohol (especially beer and spirits) and sugar-sweetened drinks, heavy meals and excessive intake of meat and seafood. Low-fat dairy products should be encouraged. Regular exercise should be advised.

C Every person with gout should be systematically screened for associated comorbidities and cardiovascular risk factors, including renal impairment, coronary heart disease, heart failure, stroke, peripheral arterial disease, obesity, hyperlipidaemia, hypertension, diabetes and smoking, which should be addressed as an integral part of the management of gout.

Final set of 11 recommendations

1 Acute flares of gout should be treated as early as possible. Fully informed patients should be educated to self-medicate at the first warning symptoms. The choice of drug (s) should be based on the presence of contraindications, the patient's previous experience with treatments, time of initiation after flare onset and the number and type of joint(s) involved.

2 Recommended first-line options for acute flares are colchicine (within 12 hours of flare onset) at a loading dose of $1 \mathrm{mg}$ followed 1 hour later by $0.5 \mathrm{mg}$ on day 1 and/or an NSAID (plus proton pump inhibitors if appropriate), oral corticosteroid (30-35 mg/day of equivalent prednisolone for 3-5 days) or articular aspiration and injection of corticosteroids. Colchicine and NSAIDs should be avoided in patients with severe renal impairment. Colchicine should not be given to patients receiving strong P-glycoprotein and/or CYP3A4 inhibitors such as cyclosporin or clarithromycin.

3 In patients with frequent flares and contraindications to colchicine, NSAIDs and corticosteroid (oral and injectable), IL-1 blockers should be considered for treating flares. Current infection is a contraindication to the use of IL-1 blockers. ULT should be adjusted to achieve the uricaemia target following an IL-1 blocker treatment for flare.

4 Prophylaxis against flares should be fully explained and discussed with the patient. Prophylaxis is recommended during the first 6 months of ULT. Recommended prophylactic treatment is colchicine, $0.5-1 \mathrm{mg} /$ day, a dose that should be reduced in patients with renal impairment. In cases of renal impairment or statin treatment, patients and physicians should be aware of potential neurotoxicity and/or muscular toxicity with prophylactic colchicine. Co-prescription of colchicine with strong P-glycoprotein and/or CYP3A4 inhibitors should be avoided. If colchicine is not tolerated or is contraindicated, prophylaxis with NSAIDs at low dosage, if not contraindicated, should be considered.

5 ULT should be considered and discussed with every patient with a definite diagnosis of gout from the first presentation. ULT is indicated in all patients with recurrent flares, tophi, urate arthropathy and/or renal stones. Initiation of ULT is recommended close to the time of first diagnosis in patients presenting at a young age ( $<40$ years) or with a very high SUA level ( $>8.0 \mathrm{mg} / \mathrm{dL} ; 480 \mu \mathrm{mol} / \mathrm{L}$ ) and/or comorbidities (renal impairment, hypertension, ischaemic heart disease, heart failure). Patients with gout should receive full information and be fully involved in decision-making concerning the use of ULT.

6 For patients on ULT, SUA level should be monitored and maintained to $<6 \mathrm{mg} / \mathrm{dL}$ ( $360 \mu \mathrm{mol} / \mathrm{L})$. A lower SUA target $(<5 \mathrm{mg} / \mathrm{dL} ; 300 \mu \mathrm{mol} / \mathrm{L})$ to facilitate faster dissolution of crystals is recommended for patients with severe gout (tophi, chronic arthropathy, frequent attacks) until total crystal dissolution and resolution of gout. SUA level $<3 \mathrm{mg} / \mathrm{dL}$ is not recommended in the long term.

7 All ULTs should be started at a low dose and then titrated upwards until the SUA target is reached. SUA $<6 \mathrm{mg} / \mathrm{dL}(360 \mu \mathrm{mol} / \mathrm{L})$ should be maintained lifelong.

8 In patients with normal kidney function, allopurinol is recommended for first-line ULT, starting at a low dose (100 $\mathrm{mg} /$ day) and increasing by $100 \mathrm{mg}$ increments every 2-4 weeks if required, to reach the uricaemia target. If the SUA target cannot be reached by an appropriate dose of allopurinol, allopurinol should be switched to febuxostat or a uricosuric or combined with a uricosuric. Febuxostat or a uricosuric are also indicated if allopurinol cannot be tolerated.

9 In patients with renal impairment, the allopurinol maximum dosage should be adjusted to creatinine clearance. If the SUA target cannot be achieved at this dose, the patient should be switched to febuxostat or given benzbromarone with or without allopurinol, except in patients with estimated glomerular filtration rate $<30 \mathrm{~mL} / \mathrm{min}$.

10 In patients with crystal-proven, severe debilitating chronic tophaceous gout and poor quality of life, in whom the SUA target cannot be reached with any other available drug at the maximal dosage (including combinations), pegloticase is indicated.

11 When gout occurs in a patient receiving loop or thiazide diuretics, substitute the diuretic if possible; for hypertension consider losartan or calcium channel blockers; for hyperlipidaemia, consider a statin or fenofibrate.

IL, interleukin; NSAID, non-steroidal anti-inflammatory drug; SUA, serum uric acid; ULT, urate-lowering therapy.

B. Every person with gout should receive advice regarding lifestyle: weight loss if appropriate and avoidance of alcohol (especially beer and spirits) and sugar-sweetened drinks, heavy meals and excessive intake of meat and seafood. Low-fat dairy products should be encouraged. Regular exercise should be advised.

Since the previous recommendations (item 2), several studies have confirmed that weight loss, achieved by dietary intervention or bariatric surgery ${ }^{29-32}$ is effective in reducing SUA level. Moreover, regular physical activity might decrease the excess mortality associated with chronic hyperuricaemia. ${ }^{33}$

In addition, the association between excessive intake of meat and alcohol with an increased risk of developing gout has been confirmed $^{293435}$ as well as increased risk of gout attacks. ${ }^{36} 37$

Importantly, other modifiable risk factors have been identified since 2006, specifically sugar-sweetened drinks, foods rich in fructose and orange or apple juice. ${ }^{38-41}$ In contrast, according to epidemiological studies, consumption of coffee, ${ }^{42-44}$ and cherries is negatively associated with gout, and eating cherries may reduce the frequency of acute gout flares. ${ }^{45}$ Studies found an inverse association between dairy intake and urate levels, particularly with skimmed milk and low-calorie yoghurt. ${ }^{34} 46$ This likely results from the uricosuric property of milk, as demonstrated in an $\mathrm{RCT}^{47}$ The benefit of dairy products, underlined in the 2006 recommendation, was reported in a RCT, suggesting that skimmed milk powder derivatives have anti-inflammatory effects against acute gout flares. ${ }^{48}$ However, impact of lifestyle and dietary modification has little effect on urate concentrations. ${ }^{49} 50$ In addition, the task force recognises that the level of evidence to support the effect of lifestyle modification on SUA levels is low, and therefore, this overarching principle was mainly based on expert opinion. However, given the high prevalence of cardiovascular comorbidities in patients with gout, lifestyle modifications should also be implemented as part of cardiovascular prevention.

C. Every person with gout should be systematically screened for associated comorbidities and cardiovascular risk factors, including renal impairment, coronary heart disease, heart failure, stroke, peripheral arterial disease, obesity, hyperlipidaemia, hypertension, diabetes and smoking, which should be addressed as an integral part of the management of gout.

The importance of screening and managing hypertension, hyperglycaemia and obesity in patients with gout was addressed in the previous recommendations (item 3). Since then, a 


\begin{tabular}{|c|c|c|c|}
\hline Item & $\begin{array}{l}\text { Category of } \\
\text { evidence }\end{array}$ & $\begin{array}{l}\text { Grade of } \\
\text { recommendation }\end{array}$ & $\begin{array}{l}\text { Level of agreement } \\
(\text { mean } \pm \text { SD) }\end{array}$ \\
\hline$A$ & NA & NA & $8.9 \pm 0.3$ \\
\hline B & NA & NA & $8.4 \pm 1.1$ \\
\hline C & NA & NA & $8.5 \pm 0.9$ \\
\hline 1 & $1 b^{*}, 4$ & $A, D$ & $8.4 \pm 1.1$ \\
\hline 2 & $1 b, 3 t$ & $A, C$ & $8.6 \pm 0.7$ \\
\hline 3 & $1 b \neq, 3 \S$ & $A, C$ & $8.1 \pm 0.9$ \\
\hline 4 & $2 b$ & B & $8.1 \pm 0.9$ \\
\hline 5 & $1 b$ & A & $8.2 \pm 0.9$ \\
\hline 6 & 3 & C & $8.8 \pm 0.5$ \\
\hline 7 & 3 & C & $8.6 \pm 0.7$ \\
\hline 8 & $1 b \|_{1}, 2 b^{* *}$ & $A, B$ & $8.8 \pm 0.4$ \\
\hline 9 & 3 & C & $8.8 \pm 0.4$ \\
\hline 10 & $1 b$ & A & $8.2 \pm 1.3$ \\
\hline 11 & 3 & C & $8.2 \pm 0.9$ \\
\hline
\end{tabular}

Ranking for category of evidence and grade of recommendation is provided in the online supplementary material.

*For the evidence that colchicine should be given as early as possible, within 12 hours of symptom onset.

tThere are no randomised controlled trials of intra-articular corticosteroid injections for flares.

‡Level of evidence for canakinumab.

$\S$ For ankinra.

ILevel of evidence for febuxostat and allopurinol.

**For uricosurics (probenecid or benzbromarone).

NA, not applicable.

number of studies have demonstrated that both hyperuricaemia and gout are associated with chronic kidney disease (CKD). ${ }^{51} 52$ In a US population-based study, the prevalence of CKD (stage $\geq 2)$ in patients with SUA level $\geq 10 \mathrm{mg} / \mathrm{dL}(594.9 \mu \mathrm{mol} / \mathrm{L})$ and in patients with gout was $86 \%$ and $53 \%$, respectively. CKD appears to be a major risk factor for gout and, conversely, gout might cause renal dysfunction. ${ }^{53}$ The task force agreed that identifying CKD in patients with gout was of major importance because of the therapeutic implications, as discussed in items 1,2 , 4, 5, 8 and 9. Therefore, estimated glomerular filtration rate (eGFR) should be calculated at the time of diagnosis for CKD classification and monitored regularly in parallel with SUA measurement. This item also emphasises the need to search for other important associated comorbidities, especially coronary heart disease, heart failure, stroke, peripheral arterial disease and diabetes because large epidemiological studies have suggested that hyperuricaemia and/or gout are independent risk factors for these conditions $^{5-63}$ and for death due to cardiovascular causes. ${ }^{17} 58$

\section{Final set of 11 recommendations on treating patients with gout}

1. Acute flares of gout should be treated as early as possible. Fully informed patients should be educated to self-medicate at the first warning symptoms. The choice of drug(s) should be based on the presence of contraindications, the patient's previous experience with treatments, time of initiation after flare onset and the number and type of joint(s) involved.

This recommendation was mainly based on expert opinion and derives from the first item of the 2006 recommendations. Because of the recognised high frequency of comorbidities and thus the high frequency of comedications in patients with gout, the task force felt that a global recommendation regarding the choice of drugs for flares based on the presence or absence of

\section{Box 1 Proposals for future research}

- Investigating the ability of low-dose NSAIDs or prednisone to prevent ULT-induced flares.

- A head-to-head trial of anakinra versus a conventional anti-inflammatory agent for the treatment of flares.

- A controlled trial of early low-dose colchicine versus early NSAIDs or oral corticosteroids or potential new drugs for flares over 1 week.

- The optimal combined therapy for treatment of an acute attack.

- The optimal duration for prophylaxis of acute attacks when starting ULT.

- Risk factors for flares when initiating ULT.

- The long-term impact of very low urate levels on the central nervous system.

- The possible benefits of XO inhibition and/or lowering serum uric acid levels for cardiovascular diseases.

- The impact of ULT on kidney function.

- The best strategy in patients with tophaceous gout.

- Direct comparison (efficacy, side effects, cost utility) between emerging uricosurics and allopurinol or febuxostat.

- The cost-utility of HLA-B ${ }^{*}$ 58:01 determination before initiating allopurinol in patients not of Asian descent.

- Imaging to visualise crystal dissolution during ULT.

- More research should be conducted in primary care. NSAID, non-steroidal anti-inflammatory drug; ULT, urate-lowering therapy.

contraindications was highly desirable. This item emphasises the importance of searching for contraindications, often present in patients with gout. One study found that more than $90 \%$ of patients had at least one contraindication to non-steroidal antiinflammatory drugs (NSAIDs) and that about one-third of patients who were prescribed colchicine had at least one major contraindication. ${ }^{64}$ This item also underlines the importance to treat as early as possible. Colchicine is effective when given within 12 hours of symptoms onset ${ }^{13}$ and there was general agreement that early initiation of any treatment for flare leads to better effectiveness. Therefore, the task force recommends the 'pill in the pocket' approach to treat flare in fully informed patients.

2. Recommended first-line options for acute flare are colchicine (within 12 hours of flare onset) at a loading dose of $1 \mathrm{mg}$ followed 1 hour later by $0.5 \mathrm{mg}$ on day 1 and/or an NSAID (plus a proton pump inhibitor if appropriate), oral corticosteroids (30-35 mg/day of equivalent prednisolone for 3-5 days) or articular aspiration and injection of corticosteroids. Colchicine and NSAIDs should be avoided in patients with severe renal impairment. Colchicine should not be given to patients receiving strong P-glycoprotein and/or CYP3A4 inhibitors such as cyclosporin or clarithromycin.

This item amalgamates the 2006 items 4-6, which have been amended in light of novel evidence. The main therapeutic options for flare are colchicine, NSAIDs and corticosteroids. The task force does not prioritise between these options because of no direct comparative evidence, but unlike 2006 item 4 , it recommends considering combination therapy, such as colchicine and an NSAID or colchicine and corticosteroids, which can be proposed for patients with particularly severe acute gout (figure 1), for instance, when flares involve multiple 
joints. In comparison to 2006 items 4 and 5, more evidence is now available in terms of the effectiveness of colchicine, ${ }^{65}$ NSAIDs $^{66-69}$ and oral corticosteroids. ${ }^{70-72}$ A double-blind, randomised equivalence trial of crystal-proven gout from a primary care source population found that prednisolone $(35 \mathrm{mg} /$ day for 5 days) was equivalent to naproxen $(500 \mathrm{mg}$ twice a day for 5 days) for treating flare. ${ }^{71} 72$ A recent trial also found that oral prednisolone $(30 \mathrm{mg} /$ day for 5 days) had analgesic effectiveness equivalent to that of indomethacin. ${ }^{70}$ The AGREE trial demonstrated that when taken within 12 hours of flare onset, selfadministrated low-dose colchicine $(1.8 \mathrm{mg})$ was as effective as high-dose colchicine $(4.8 \mathrm{mg})$ but with a safety profile comparable to that of a placebo. ${ }^{65}$ In Europe, colchicine is available in
$1 \mathrm{mg}$ tablets, so the task force recommends the use of $1 \mathrm{mg}$ colchicine followed 1 hour later by $0.5 \mathrm{mg}$ for treating flare. A pharmacokinetic study ${ }^{73}$ showed that strong P-glycoprotein and/or CYP3A4 inhibitors such as cyclosporin, clarithromycin, verapamil and ketoconazole when prescribed with colchicine increased colchicine plasma concentration, thereby exposing patients to risk of serious side effects. The safe use of colchicine in patients with severe renal impairment (GFR $<30 \mathrm{~mL} / \mathrm{min}$ ) has not been established. Because colchicine clearance is decreased in patients with severe renal impairment, ${ }^{74}$ the group considered that it should be avoided in these patients, because a reduced dosage ${ }^{73}$ might be a source of therapeutic misuse. In addition, it should be noted that colchicine is

\section{EULAR RECOMMENDATION FOR THE MANAGEMENT OF FLARES} IN PATIENTS WITH GOUT

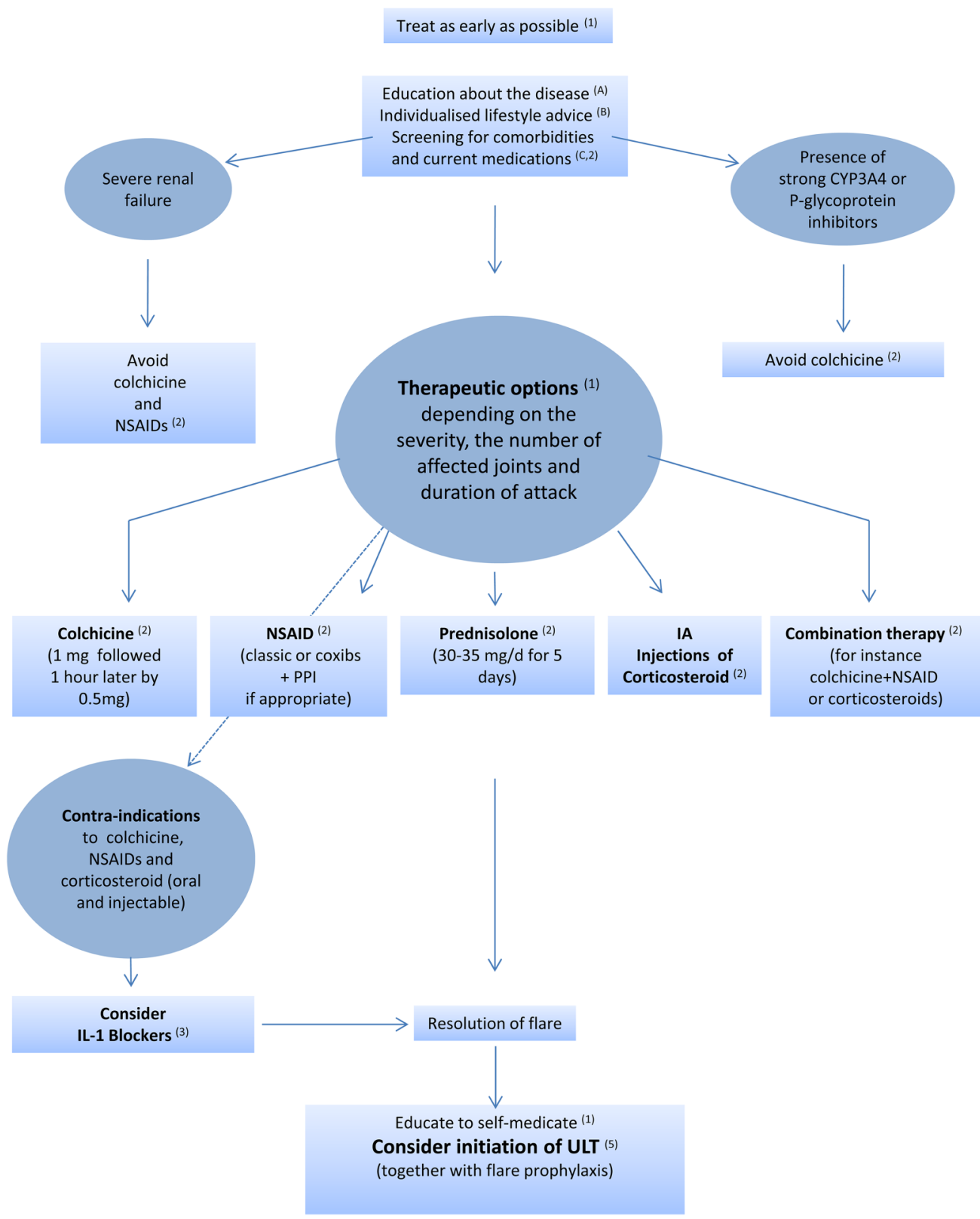

Figure 1 Management of acute flare according to the European League Against Rheumatism recommendations. Letters and numbers in parentheses indicate the items of the recommendations presented in table 1. Strong P-glycoprotein or CYP3A4 inhibitors are cyclosporin, clarithromycin, ketoconazole and ritonavir. IL, interleukin; NSAID, non-steroidal anti-inflammatory drug; PPI, proton pump inhibitor; ULT, urate-lowering therapy. 
contraindicated in some countries in patients with severe renal failure. From data from two RCTs, ${ }^{71} 72$ the group also recommends the use of oral prednisolone at $30-35 \mathrm{mg}$ for 5 days for treating flare. Finally, from data from an open trial ${ }^{76} 77$ and expert opinion, the group considered that intra-articular injection of corticosteroids, which has a good safety profile, should be considered particularly in patients with monoarthritis of an easily accessible joint, although acknowledging that this may not be practical in many primary care settings.

3. In patients with frequent flares and contraindications to colchicine, NSAIDs and corticosteroids (oral and injectable), IL-1 blockers should be considered for treating flares. Current infection is a contraindication to the use of IL-1 blockers. ULT should be adjusted to achieve the uricaemia target following IL-1 blocker treatment for flare.

Since the last 2006 recommendations, IL-1 $\beta$ was found to play a crucial role in monosodium urate (MSU) crystal-induced inflammation. ${ }^{78}$ Two RCTs have reported that the anti-IL-1 $\beta$ monoclonal antibody canakinumab (150 mg subcutaneously, one dose) was superior to triamcinolone acetonide (40 mg subcutaneously, one dose) in reducing pain in patients with flare with contraindication, intolerance of or non-response to NSAIDs and/or colchicine. ${ }^{79}$ These findings led to approval of the drug in Europe solely in patients with contraindication to colchicine, NSAIDs and steroids. Despite the lack of RCTs of anakinra, a case series also suggest that this IL-1 receptor antagonist, administered subcutaneously at $100 \mathrm{mg}$ for 3 days, could be effective in reducing pain in patients with acute attacks. ${ }^{80-83}$ By contrast, an RCT demonstrated that one subcutaneous injection of rilonacept, $320 \mathrm{mg}$, a soluble receptor fusion protein binding both IL- $1 \alpha$ and IL- $1 \beta,{ }^{84}$ provided no benefit over indomethacin (oral, $50 \mathrm{mg}$, three times a day for 3 days) ${ }^{85}$ Because of the risk of sepsis in patients receiving IL-1 blockers, ${ }^{86}$ the task force considered current infection a contraindication to the use of anti-IL-1 biologics, which implies screening for occult infections. Finally, in accordance with the European Medicines Agency labelling of canakinumab, the group stressed the need to effectively lower SUA level in these patients with severe gout once the flare resolved following IL-1 $\beta$ blockade.

4. Prophylaxis against flares should be fully explained and discussed with the patient. Prophylaxis is recommended during the first 6 months of ULT. Recommended prophylactic treatment is colchicine, $0.5-1 \mathrm{mg} /$ day, a dose that should be reduced in patients with renal impairment. In cases of renal impairment or statin treatment, patients and physicians should be aware of potential neurotoxicity and/or muscular toxicity with prophylactic colchicine. Co-prescription of colchicine with strong P-glycoprotein and/or CYP3A4 inhibitors should be avoided. If colchicine is not tolerated or is contraindicated, prophylaxis with NSAIDs at a low dosage, if not contraindicated, should be considered.

Dispersion of MSU crystals during the initial phase of deposit dissolution may expose the patient to increased rate of acute flare that can contribute to poor treatment adherence. ${ }^{87}$ The 2006 recommendations (item 11) mentioned that prophylactic treatment should be given during the first months of ULT. Since then, data from pivotal trials of febuxostat versus a fixed dose of allopurinol $(300 \mathrm{mg})$ found that flare prophylaxis with low-dose colchicine (colchicine, $0.6 \mathrm{mg} /$ day) or low-dose NSAID (naproxen, $250 \mathrm{mg}$ twice daily) for up to 6 months appeared to provide greater benefit than flare prophylaxis for 8 weeks, with no increase in adverse events. ${ }^{88}$ However, the task force felt that initiation of prophylaxis should be discussed with every patient. Indeed, a study found that following patient education and with slow upward titration of ULT, mostly allopurinol, many patients chose not to take prophylaxis and did not experience a significantly greater flare rate. ${ }^{28}$ This recommendation also explicitly underlines the need to search for renal impairment before prescribing colchicine ${ }^{75}$ and co-prescription with statins ${ }^{89}$ and P-glycoprotein and/or CYP3A4 inhibitors ${ }^{73}$ to avoid serious side effects. Of note, two RCTs found that low-dose colchicine in patients with a history of coronary heart disease could reduce the incidence of major cardiovascular events. ${ }^{90} 91$ Reports for several trials described the efficacy of canakinumab and rilonacept, ${ }^{92-96}$ two IL-1 inhibitors, for preventing flares during the initiation of allopurinol therapy. However, none of them has been approved for prophylactic treatment.

5. ULT should be considered and discussed with every patient with a definite diagnosis of gout from the first presentation. ULT is indicated in all patients with recurrent flare ( $\geq 2 /$ year), tophi, urate arthropathy and/or renal stones. Initiation of ULT is recommended close to the time of first diagnosis in patients presenting at a young age (<40 years), or with a very high SUA level (>8 mg/dL; $480 \mu \mathrm{mol} / \mathrm{L})$ and/or comorbidities (renal impairment, hypertension, ischaemic heart disease, heart failure). Patients with gout should receive full information and be fully involved in decision-making concerning the use of ULT.

ULT allows for dissolving crystal deposits and the disappearance of gout features, as long as uricaemia is maintained to target. Since 2006, large trials have shown that appropriate ULT reduces the frequency of gout flare and once all crystals have been dissolved, avoids their reoccurrence. ${ }^{97-99}$ In addition, effective ULT reduces the size and number of tophi ${ }^{97} 99100$ and facilitates their disappearance, thereby improving the quality of life of patients with gout, ${ }^{101} 102$ which can be seriously impaired by the disease. ${ }^{103-106}$

Several studies concur in showing that gout is a risk factor for mortality, in particular from cardiovascular causes, ${ }^{17} 107108$ and a risk factor for kidney impairment ${ }^{51}$ as discussed previously (see the third overarching principle).

Unlike the 2006 guideline in which the group of experts recommended starting ULT only for patients with certain severe clinical features, including recurrent acute attacks and tophi (item 7), the current task force recommends possible initiation of ULT close to the first presentation (ie, in most cases, close to the first attack). Indeed, the task force felt that delaying initiation of ULT until the second or third attack would expose patients to a higher crystal load, for difficulties in dissolution and to longstanding hyperuricaemia, which may be deleterious for the cardiovascular system and kidney. ${ }^{5156} 107-110$ Therefore, the recommendation to initiate ULT earlier was mainly based on expert opinion but also took into account studies that suggest a cardiovascular $^{111} 112$ and renal benefit ${ }^{113-116}$ from xanthine oxidase inhibitors (XOI). XO inhibition improved exercise capacity in patients with chronic stable angina in a randomised cross-over trial. ${ }^{117}$ Epidemiological studies suggested that allopurinol might decrease morbidity and mortality in patients with congestive heart failure and a history of gout, ${ }^{118}{ }^{119}$ a benefit not confirmed in a recent randomised trial of patients with heart failure and hyperuricaemia without gout. ${ }^{120}$ In addition, pharmaco-epidemiological studies report that allopurinol use is associated with an approximately $20 \%$ reduction in myocardial infarction risk. ${ }^{121} 122$ However, the task force acknowledged that additional well-conducted trials are warranted in this field, as recent studies yielded conflicting results. $^{123} 124$ 
Item 5 also underlines the need to start ULT early, particularly in patients with comorbidities and/or SUA level $>8 \mathrm{mg} / \mathrm{dL}$. Encouragement to treat patients with high SUA level earlier is based on studies showing an association of high uricaemia with increased flare frequency. ${ }^{125-127}$ Similarly, early treatment in patients with comorbidities is supported by a study of a large cohort of gout patients finding hypertension, ischaemic heart disease and CKD all associated with increased risk of recurrence of flare. ${ }^{128}$ Young age at gout onset is also a marker of gout severity ${ }^{129}$ and should also prompt earlier treatment. This recommendation underlines again the importance of providing full information and involving the patient in the decision-making process, to ensure adherence to ULT and optimal patient-centred outcomes.

Finally, the task force did not give specific guidance on whether urate-lowering drugs should be initiated during a flare or whether a traditional 2 weeks delay from flare termination should be observed. Two small trials have suggested that allopurinol initiation during an acute gout attack did not prolong the duration of flares nor worsen its severity as compared with delayed initiation. ${ }^{130} 131$ However, the task force considered that the low number of patients ( $\mathrm{n}=51$ and $\mathrm{n}=31$, respectively) in these trials precluded any firm conclusions and that data obtained with allopurinol 200-300 mg could not be generalised to more potent urate-lowering drugs, such as febuxostat or a combination of XOI and an uricosuric.

6. For patients on ULT, SUA level should be monitored and maintained to $<6 \mathrm{mg} / \mathrm{dL}(360 \mu \mathrm{mol} / \mathrm{L})$. A lower SUA target $(<5 \mathrm{mg} / \mathrm{dL} ; 300 \mu \mathrm{mol} / \mathrm{L})$ to facilitate faster dissolution of crystals is recommended for patients with severe gout (tophi, chronic arthropathy, frequent attacks) until total crystal dissolution and resolution of gout. SUA level $<3 \mathrm{mg} / \mathrm{dL}$ is not recommended in the long term.

As in 2006 (item 8), the task force recommends a treat-to-target strategy for every patient with gout, to maintain the SUA level $<6 \mathrm{mg} / \mathrm{dL}$, which is below the saturation point for $\mathrm{MSU}^{132}$ to dissolve all crystal deposits. ${ }^{133}$ Because the velocity of crystal dissolution depends on the SUA level, ${ }^{134} 135$ the task force also recommends reducing the SUA level to $<5 \mathrm{mg} / \mathrm{dL}$ for severe gout reflecting high crystal load until total crystal dissolution has occurred. The task force also agreed that once dissolution of crystals is achieved, SUA level could be maintained $<6 \mathrm{mg} / \mathrm{dL}$ by a reduction in the dose of ULT to avoid new formation of urate crystals.

Some studies, but not all, ${ }^{136-138}$ have suggested that uric acid might protect against various neurodegenerative diseases such as Parkinson's disease, Alzheimer's disease or amyotrophic lateral sclerosis. ${ }^{139-142}$ Given these data and the availability of ULT that has the potency to greatly decrease SUA levels, the task force does not recommend lowering continuously the SUA level to $<3 \mathrm{mg} / \mathrm{dL}$ in the long term that is, for several years.

7. All ULTs should be started at a low dose and then titrated upward until the SUA target is reached. SUA $<6 \mathrm{mg} / \mathrm{dL}$ (360 $\mu \mathrm{mol} / \mathrm{L})$ should be maintained lifelong.

The task force recommends upward titration of ULT in every patient when feasible. This approach, mentioned in 2006 (item 9), might result in fewer episodes of acute flares during treatment initiation $^{28}$ and therefore improved adherence to ULT, which is low according to several studies. ${ }^{27} 143{ }^{144}$ Following complete dissolution of MSU crystals, the SUA level should be maintained at $<6 \mathrm{mg} / \mathrm{dL}$ lifelong. Indeed, a study showed that about $40 \%$ of successfully treated patients show recurrence of flare 5 years after withdrawal of ULT. ${ }^{145}$ Therefore, determining SUA level on a regular basis is a key aspect of treatment.
8. In patients with normal kidney function, allopurinol is recommended for first-line ULT, starting at a low dose $(100 \mathrm{mg} /$ day $)$ and increasing by $100 \mathrm{mg}$ increments every 2-4 weeks if required, to reach the uricaemic target. If the SUA target cannot be reached by an appropriate dose of allopurinol, allopurinol should be switched to febuxostat or a uricosuric, or combined with a uricosuric. Febuxostat or a uricosuric are also indicated if allopurinol cannot be tolerated.

As in 2006 (item 9), the task force recommends the use of allopurinol as first-line therapy in patients with normal kidney function. This recommendation takes into account the efficacy, low cost and safety of this drug. Since 2006, two RCTs have confirmed the superior urate-lowering efficacy of allopurinol $\left(300 \mathrm{mg} /\right.$ day) over placebo. ${ }^{97}{ }^{130}$ Medico-economic studies of ULT reported that a dose-escalation strategy with allopurinol as first-line therapy was cost-effective. ${ }^{146} 147$ Allopurinol should be started at a low dose $(100 \mathrm{mg} /$ day $)$ to reduce early gout flare ${ }^{28}$ and because high starting doses might increase the risk of serious cutaneous adverse reactions (SCARs). ${ }^{15}$ The most commonly used allopurinol dose of $300 \mathrm{mg} /$ day does not achieve the SUA target of $6 \mathrm{mg} / \mathrm{dL}(360 \mu \mathrm{mol} / \mathrm{L})$ in about $30 \%-50 \%$ of patients with normal kidney function. ${ }^{28} 148149$ For those patients, the task force recommends a dose-escalation strategy to increase the dose in order to reach the predefined uricaemia target. Treatment with allopurinol up to $600-800 \mathrm{mg} /$ day had a $75 \%-80 \%$ success rate of achieving SUA levels of $<6 \mathrm{mg} / \mathrm{dL}$ $(360 \mu \mathrm{mol} / \mathrm{L}){ }^{28}{ }^{150}$

Febuxostat is a potent non-purine selective XOI approved at daily doses of 80 and $120 \mathrm{mg}$ in Europe. It is metabolised in the liver and renal excretion is not a major route of elimination, which allows for its use in patients with mild-to-moderate kidney failure. A short-term phase II trial ${ }^{151}$ and three large RCTs (see online supplementary material) showed superior urate-lowering efficacy with febuxostat $(80$ or $120 \mathrm{mg}$ ) as compared with the commonly used fixed daily dose of $300 \mathrm{mg}$ allopurinol. $^{97} 98149$ Cutaneous reactions have been described in pivotal trials with febuxostat. ${ }^{97} 149$ Despite case reports of SCARs in patients receiving febuxostat, ${ }^{152}{ }^{153}$ recent data do not support any cross-reactivity between the two drugs. ${ }^{153} 154$ Therefore, the task force considered that a history of allergic reaction to allopurinol was not a contraindication to febuxostat, but underlined the need to carefully follow these patients.

Uricosurics are recommended, where available, alone or in combination with allopurinol in patients without proper control with allopurinol alone. Benzbromarone $(50-200 \mathrm{mg} /$ day $)$ is a more potent uricosuric as compared with probenecid $(1-2 \mathrm{~g} /$ day $) .{ }^{155}$ In an RCT of patients without proper control with allopurinol, $300 \mathrm{mg} /$ daily, $92 \%$ and $65 \%$ of patients reached a SUA target of $300 \mu \mathrm{mol} / \mathrm{L} \quad(5 \mathrm{mg} / \mathrm{dL})$ when switched to benzbromarone, $200 \mathrm{mg}$, or probenecid, $2 \mathrm{~g}$ daily, respectively. ${ }^{148}$ Finally, the recommendation for combination therapy with allopurinol and a uricosuric, not mentioned in 2006, is based on uncontrolled trials that have suggested that probenecid-allopurinol ${ }^{156-158}$ or benzbromarone-allopurinol ${ }^{135}$ was more effective than allopurinol alone. Furthermore, emerging uricosuric, such as lesinurad, ${ }^{159}$ has shown promising results in a phase II trial when combined with allopurinol. ${ }^{160}$

9. In patients with renal impairment, the allopurinol maximum dosage should be adjusted to creatinine clearance. If the SUA target cannot be achieved at this dose, the patient should be switched to febuxostat or given benzbromarone with or without allopurinol, except in patients with eGFR $<30 \mathrm{~mL} / \mathrm{min}$. 
This item retained the 2006 recommendation (item 9) to adjust the allopurinol dosage according to the creatinine clearance. The greatest concern with the use of allopurinol in patients with renal failure is the development of SCARs, which includes drug rash with eosinophilia and systemic symptoms, Stevens-Johnson syndrome (SJS) and toxic epidermal necrosis. Since 2006, several studies have further explored allopurinol-induced SCARs. Allopurinol was found to be the most common drug associated with SJS or toxic epidermal necrolysis in Europe. ${ }^{161}$ Allopurinol-induced SCARs are rare, the incidence rate being about $0.7 / 1000$ patient-years in allopurinol initiators in the USA, ${ }^{162}$ but the mortality rate is high (25\%-30\%). ${ }^{163-165}$

Renal failure has been associated with an increased risk of SCARs and poor outcome. ${ }^{163} 164$ Decreased renal function results in decreased clearance and higher serum levels of oxypurinol, ${ }^{164} 166$ which could induce a cytotoxic T-cell response and trigger hypersensitivity reactions in SCARs. ${ }^{167}$ In some studies, dose escalation of allopurinol above the limit allowed by creatinine clearance did not result in SCARs, ${ }^{14}{ }^{168}$ but given the very low incidence of SCARs and the limited number of patients involved in these studies, the task force considered that they probably lacked power to detect a potential association.

Therefore, given the extreme severity of SCARs and the possibility of therapeutic alternatives such as febuxostat, the task force retained the conservative approach to adjust the maximum dose of allopurinol to the creatinine clearance ${ }^{169}$ in patients with renal impairment, as required by most regulatory agencies. Because the dose recommendations in renal disease may slightly differ across countries, the task force recommends to follow the local Summary of Product Characteristics.

Febuxostat has been found more effective in patients with CKD than allopurinol given at doses adjusted to creatinine clearance $^{149170}$ and therefore can be used in these patients. Finally, benzbromarone is not recommended for use in patients with eGFR $<30 \mathrm{~mL} / \mathrm{min}$, but can be used in patients with moderate renal impairment ${ }^{171} 172$ because it is predominately metabolised by the liver.

10. In patients with crystal-proven severe debilitating chronic tophaceous gout and poor quality of life, in whom the SUA target cannot be reached with any other available drug at the maximal dosage (including combinations), pegloticase is indicated.

Since the last EULAR recommendation, pegloticase has emerged as a powerful ULT for refractory gout. Pegloticase is a pegylated uricase, produced by a genetically modified strain of Escherichia coli that catalyses the oxidation of uric acid into allantoin, a more soluble end product. ${ }^{173}$ Its efficacy has been assessed in two replicate 6-month, randomised, double-blind, placebo-controlled, phase III trials. ${ }^{99} 100$ In this study, the percentage of responders (SUA level $<6 \mathrm{mg} / \mathrm{dL}$ ) was $42 \%$, on average, in patients who received pegloticase, $8 \mathrm{mg}$, every 2 weeks and $0 \%$ in the placebo group. Allergic reactions, possibly related to the occurrence of antibody against pegloticase, ${ }^{174}$ were observed in about $25 \%$ of patients who received pegloticase biweekly. Given the safety profile of pegloticase and the demonstration of its efficacy in patients with refractory gout, the task force recommends its use in patients with clinically severe crystal-proven gout that cannot be properly treated with conventional ULT, including a combination of an XOI and a uricosuric agent. There was no firm agreement with regards to the duration of treatment with pegloticase. However, there was a consensus to consider a switch, if feasible, toward an oral ULT once all tophi had disappeared.
11. When gout occurs in a patient receiving loop or thiazide diuretics, substitute the diuretic if possible; for bypertension, consider losartan or calcium channel blockers; for byperlipidaemia, consider a statin or fenofibrate.

This recommendation is similar to the 12th 2006 recommendation. However, in addition to losartan, the task force now recommends consideration of calcium blockers in patients with gout. This recommendation is supported by a large epidemiological study finding relative risks of incident gout associated with the current use of calcium channel blockers and losartan of 0.87 (95\% CI 0.82 to 0.93 ) and 0.81 (95\% CI 0.70 to 0.94$)$, respectively. ${ }^{175}$ Finally, the uricosuric property of fenofibrate ${ }^{176} 1^{177}$ and statins has been further documented. ${ }^{178} 179$

\section{DISCUSSION}

These updated EULAR recommendations aim to provide physicians-rheumatologists, GPs and others-with the best pragmatic strategies to manage hyperuricaemia and flare in patients with gout (figures 1 and 2).

As first-line care providers, GPs have a predominant role in gout treatment. Likewise, the involvement of patients in the management of chronic diseases is crucial. Therefore, in contrast to 2006, the current task force included two GPs and two patients to broaden the involvement of stakeholders involved in the disease. As mentioned previously, gout is mainly managed by GPs, and the task force recognises that we lack trials conducted in primary care; most of the RCTs analysed in this paper were conducted in tertiary care. Overall, this set of recommendations was well graded by external GPs and rheumatologists (see online supplementary material).

Since 2006, the perception of gout has changed. The increase in prevalence of gout in developed countries, ${ }^{1-3} 180$ the severity of the arthritis itself, ${ }^{6}$ and the increasing evidence for an association between gout with cardiovascular events, kidney failure and mortality have heightened the realisation that gout should never be neglected and should be treated properly. ${ }^{6}$ Furthermore, since 2006, the treatment armamentarium has greatly expanded, with the approval of both febuxostat and pegloticase, the demonstration of the efficacy of IL-1 blockers to treat flare and the emergence of novel ULTs. ${ }^{11}{ }^{12}{ }^{181}$ As expected, the task force modified all the previous 2006 recommendation items to incorporate all these recent developments and altered perspectives that have resulted from recent research evidence.

As compared with 2006, the key differences in terms of the therapeutic strategy for the management of hyperuricaemia are the recommendations to titrate and initiate ULT very early in the course of the disease, to combine an XOI and a uricosuric, and for patients with severe gout to reach a target SUA level of $5 \mathrm{mg} / \mathrm{dL}(300 \mu \mathrm{mol} / \mathrm{L})$ to hasten crystal dissolution. The task force was convinced that treatment of hyperuricaemia should be target-oriented and initiated without delay to avoid a further longstanding period of silent urate deposits. ${ }^{182-184}$ In addition, a 'start low, go slow' approach is recommended, because it probably results in fewer episodes of acute gout during treatment initiation and therefore might improve ULT adherence.

The task force was aware that not all ULTs mentioned in this paper, especially the uricosurics, are readily available in all European countries. However, it felt that these older drugs, in the absence of available new ULTs, could benefit some patients without adequate control with allopurinol or febuxostat alone. Of note, the recommendation to combine benzbromarone or 
2016 EULAR RECOMMENDATION FOR THE MANAGEMENT OF HYPERURICEMIA IN PATIENTS WITH GOUT

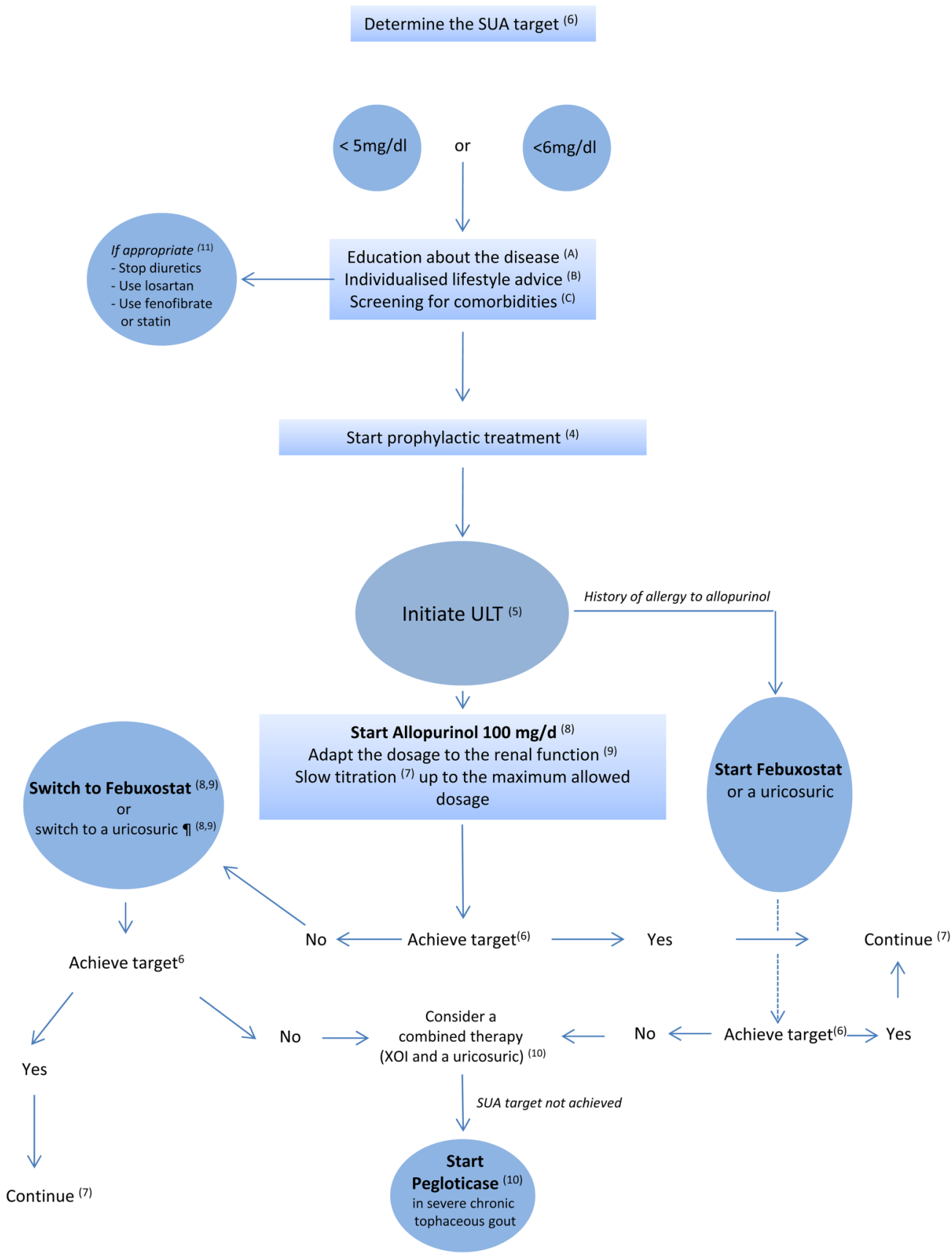

Figure 2 Management of hyperuricaemia in patients with gout according to the European League Against Rheumatism recommendations. Letters and numbers in parentheses refer to the items of the recommendations presented in table 1. SUA, serum uric acid; ULT, urate-lowering therapy; XOI, xanthine oxidase inhibitor. ๆAt this stage, combined allopurinol and a uricosuric is also recommended.

probenecid with an XOI is a novel strategy that should help physicians manage severe gout that is not readily controlled by single agents and not eligible for pegloticase. This recommendation was not strictly evidence-based and relied more on expert opinion and on recent data from phase II trials showing the potency to combine allopurinol or febuxostat with lesinurad, a novel uricosuric targeting URAT1. ${ }^{11} 160$

These revised EULAR recommendations differ in some aspects from the 2012 American College of Rheumatology (ACR) guidelines. ${ }^{185} 186$ For instance, ACR recommends allopurinol or febuxostat as first-line therapy, whereas EULAR recommends allopurinol first and then febuxostat with failure to achieve the predetermined SUA target. As indicated previously, this recommendation was not supported by efficacy data, but rather took into account the cost and effectiveness of both drugs at their optimal dosage as well as regulatory rules endorsed in several European countries. Importantly, unlike the ACR, the EULAR recommends adjusting the dosage of allopurinol to the creatinine clearance in patients with renal failure, owing to an increased risk of SCARs in those patients, ${ }^{164}$ and febuxostat as an alternative if the SUA target is not reached.

The ACR also recommended that ULT could be started during an acute attack ${ }^{185}$ if anti-inflammatory treatment had been introduced, a strategy not recommended in the present paper. 
These recommendations also did not mention systematic HLA-B*5801 screening before the initiation of allopurinol. This haplotype is the strongest risk factor for allopurinol-induced SCARs, ${ }^{187}$ and oxypurinol, the serum levels of which are increased in patients with renal failure, ${ }^{164}$ can preferentially bind to the peptide binding groove of HLA-B*58:01 and dose-dependently activate $\mathrm{T}$ cells. ${ }^{188}{ }^{189}$ The association between carriage of this allele and increased risk of SCARs has been mainly observed in certain ethnic populations, including Han Chinese, Thai and Korean patients, showing high allele frequency. ${ }^{187}$ By contrast, in Europe, where the allele frequency is much lower, allopurinol-induced SCARs have been reported also in the absence of this haplotype. ${ }^{190}$ Although studies conducted in Asia found that screening for HLA-B*58:01 was cost-effective ${ }^{191} 192$ and reduced the incidence of allopurinolinduced SCARs, ${ }^{159}$ the task force felt that we lack sufficient data to provide firm recommendations for cost-effective screening in populations with low allele frequency, such as Europe. Therefore, screening for this haplotype before initiating allopurinol is left to the discretion of the attending physician, who should however be aware of the genetic risk of severe allergic reaction conferred by HLA-B*58.01 carriage.

Recommendations for the treatment of flares have also markedly evolved since 2006 in that use of colchicine should be tailored according to current medications and comorbidities, oral corticosteroids can be offered and a combination of antiinflammatory agents is now recommended depending on the severity of flares. Items related to colchicine, NSAIDs and oral corticosteroids are now predominantly evidence-based, whereas those related to combined therapy and intra-articular corticosteroid injections rely on expert and patient opinion, which highlights the need for further trials. The other main novelty for treatment of flares is the recommendation for IL-1 blockade in patients with frequent, poorly controlled flares. Given the price and putative infection risk associated with IL-1 blockers, the task force recommends their use in patients with contraindications to colchicine, NSAIDs and corticosteroids. Finally, the need to educate patients and to promote a 'pill-in-the-pocket' approach is highlighted to provide rapid treatment of flares, because the task force is convinced that patients must play a key role and be fully involved in the management of their disease.

These novel EULAR recommendations will undoubtedly require updating over the next few years. Indeed, we anticipate that new data on existing drugs or emerging drugs, in particular novel uricosurics, will be available soon. In addition, studies of therapeutic strategies are likely to emerge. The task force sincerely hopes that these pragmatic recommendations will improve the current quality of gout care.

\section{Author affiliations}

${ }^{1}$ AP-HP, hôpital Lariboisière, service de Rhumatologie, F-75010 Paris, France; Inserm, UMR1132, Hôpital Lariboisière, F-75010 Paris, France; Universitè Paris Diderot, Sorbonne Paris Citè, F-75205 Paris, France

${ }^{2}$ Academic Rheumatology, University of Nottingham, Nottingham, UK

${ }^{3}$ Department of Rheumatology, Hospital General Universitario de Alicante, Alicante, Spain

${ }^{4}$ Institute of Rheumatology RAMS, Moscow, Russia

${ }^{5}$ Department of Diagnostic and Interventional Radiology, Lausanne University Hospital, Lausanne, Switzerland

${ }^{6}$ AP-HP, Dèpartement d'Epidèmiologie et Recherche Clinique, Hôpital Bichat, Paris, France: APHP, Centre de Pharmacoèpidèmiologie, Paris, France: Univ Paris Diderot, Paris, France: INSERM UMR 1123 ECEVE, Paris, France

${ }^{7}$ Patient from Nottingham, UK, Paris

${ }^{8}$ Department of Rheumatology, VieCuri Medical Centre, Venlo, and Scientific IQ HealthCare, Radboud UMC, Nijmegen, The Netherlands

${ }^{9}$ Department of Primary and Community Care, Radboud University Medical Centre, Nijmegen, Netherlands
}

${ }^{10}$ Arthritis Research UK Primary Care Centre University of Keele, Keele, UK

${ }^{11}$ Osteoarticular Research Group, University of Edinburgh, Edinburgh, UK

${ }^{12}$ Seccion de Rheumatologia, Hospital de Cruces, Baracaldo, Spain

${ }^{13}$ Rheumatology Unit, Clínica Coração de Jesus, Lisbon, Portugal

${ }^{14}$ Rheumatology Unit, University of Padova, Padova, Italy

${ }^{15}$ Service de Rhumatologie, CHUV and Universitè de Lausanne, Lausanne, Switzerland

${ }^{16}$ Department of Rheumatology, University Clinic at the Technical University Dresden, Germany

${ }^{17}$ Department of Rheumatology, Diakonhjemmet Hospital, Oslo, Norway

${ }^{18}$ Institute of Rheumatology, Prague, and Department of Rheumatology, First Faculty of Medicine, Charles University in Prague, Czech Republic

Acknowledgements This paper is dedicated to the memory of Dr Victoria Barskova. We are grateful to the external GPs and rheumatologists who read and/or rated these recommendations: Burchert-Mainz@t-online.de; a.hagenow@ansb.de; Uta.Kiltz@elisabethgruppe.de; graham@davenport1.plus.com; emwise@doctors.org. uk; philip.courtney@nuh.nhs.uk; m.kloppenborg@wxs.nl; wendyvantuij|@kpnmail.nl; mjanssen@rijnstate.nl; bohumil.seifert@svl.cz; ondrej.viklicky@ikem.cz; marianpou@gmail.com; cesardiaztorne@gmail.com; anarita.rferreira@gmail.com; eunicecarrapico@gmail.com; inescrispin@hotmail.com; jacques.malghem@uclouvain. be; franz.kainberger@billrothhaus.at; marco.zanetti@hirslanden.ch; danielguntern@hotmail.com; e.roddy@keele.ac.uk; Tove.Borgen@diakonsyk.no; hbham@online.no; LarsFridtjof.Karoliussen@diakonsyk.no; gerard. chales@chu-rennes.fr; docteur.auber@@gmail.com; gilleserrieau@yahoo.fr.

Contributors All authors have contributed to this work and approved the final version.

Competing interests PR received fees from Ipsen Pharma/Menarini, AstraZeneca and Savient. MD has received honoraria for ad hoc advisory boards on gout or osteoarthritis from Ardea BioSciences, AstraZeneca, Nordic BioSciences and Roche and $\mathrm{Cl}$ for a Nottingham University Investigator-led non-drug study on gout funded by AstraZeneca. EP received fees from Ipsen Pharma/Menarini and AstraZeneca. TLJ received fees for lectures and/or advisory boards from AstraZeneca, AbbVie, BMS, Janssen, Eli Lilly, Menarini, Novartis, Pfizer, Roche, UCB. FL received fees for advisory boards: Ardea BioSciences, AstraZeneca global, AstraZeneca France, Ipsen Pharma, Menarini International, Menarini France, Novartis France, Novartis Global, Savient, Mayoly Spindler. He also had unrestricted grants for organising the European Crystal Workshops (Convenor Frédéric Lioté, France \& Alexander SO, Switzerland) since 2010: Ardea BioSciences, AstraZeneca global, AstraZeneca France, Ipsen Pharma, Novartis France, Novartis Global, Mayoly Spindler, Savient, SOBI France, SOBI International. He received fees for lectures from Ardea BioSciences, Ipsen Pharma, Menarini France, Novartis Global. GN received fees from Savient, Ipsen and Menarini. FP-R has received fees from Ipsen Pharma, Menarini and AstraZeneca. LP has received consulting or speaker fees from Menarini, Fidia, AbbVie, Merck. AS has served as consultant to AstraZeneca and SOBI in regards to the treatment of gout. AKT received fees from Berlin Chemie-Menarini, Novartis and AstraZeneca/Ardea BioSciences. TU received fees from Novartis and AstraZeneca/ Ardea. JZ received fees from Berlin Chemie-Menarini and Novartis, both $<$ US $\$ 1000$. WZ received honorarium from Savient as part of the Advisory Board for Pegloticase. TB has received consulting fees, speaker fees or grants from Ipsen Pharma, Menarini, AstraZeneca, Novartis, SOBI, Savient and CymaBay.

Provenance and peer review Not commissioned; externally peer reviewed.

\section{REFERENCES}

1 Bardin T, Bouée S, Clerson P, et al. Prevalence of gout in the Adult Population of France. Arthritis Care Res (Hoboken) 2016;68:261-6.

2 Trifirò G, Morabito P, Cavagna L, et al. Epidemiology of gout and hyperuricaemia in Italy during the years 2005-2009: a nationwide population-based study. Ann Rheum Dis 2013;72:694-700.

3 Kuo CF, Grainge MJ, Mallen C, et al. Rising burden of gout in the UK but continuing suboptimal management: a nationwide population study. Ann Rheum Dis 2015;74:661-7.

4 Roddy E, Doherty M. Epidemiology of gout. Arthritis Res Ther 2010;12:223.

5 Kuo CF, Grainge MJ, Zhang W, et al. Global epidemiology of gout: prevalence, incidence and risk factors. Nat Rev Rheumatol 2015;11:649-62.

6 Doherty M, Jansen TL, Nuki G, et al. Gout: why is this curable disease so seldom cured? Ann Rheum Dis 2012;71:1765-70.

7 Richette $\mathrm{P}$, Clerson P, Périssin L, et al. Revisiting comorbidities in gout: a cluster analysis. Ann Rheum Dis 2015;74:142-7.

8 Zhang W, Doherty M, Bardin T, et al. EULAR evidence based recommendations for gout. Part II: Management. Report of a task force of the EULAR Standing Committee for International Clinical Studies Including Therapeutics (ESCISIT). Ann Rheum Dis 2006;65:1312-24.

9 So A, Thorens B. Uric acid transport and disease. J Clin Invest 2010;120:1791-9.

10 Rock KL, Kataoka H, Lai JJ. Uric acid as a danger signal in gout and its comorbidities. Nat Rev Rheumatol 2013;9:13-23. 
11 Diaz-Torné C, Perez-Herrero N, Perez-Ruiz F. New medications in development for the treatment of hyperuricemia of gout. Curr Opin Rheumatol 2015;27:164-9.

12 Edwards NL, So A. Emerging therapies for gout. Rheum Dis Clin North Am 2014:40:375-87.

13 Terkeltaub RA. Colchicine update: 2008. Semin Arthritis Rheum 2009;38:411-19.

14 Stamp LK, O'Donnell JL, Zhang M, et al. Using allopurinol above the dose based on creatinine clearance is effective and safe in patients with chronic gout, including those with renal impairment. Arthritis Rheum 2011;63:412-21.

15 Stamp LK, Taylor WJ, Jones PB, et al. Starting dose is a risk factor for allopurinol hypersensitivity syndrome: a proposed safe starting dose of allopurinol. Arthritis Rheum 2012;64:2529-36.

16 Hung SI, Chung WH, Liou LB, et al. HLA-B*5801 allele as a genetic marker for severe cutaneous adverse reactions caused by allopurinol. Proc Natl Acad Sci USA 2005;102:4134-9

17 Perez-Ruiz F, Martínez-Indart L, Carmona L, et al. Tophaceous gout and high leve of hyperuricaemia are both associated with increased risk of mortality in patients with gout. Ann Rheum Dis 2014;73:177-82.

18 Dougados M, Betteridge N, Burmester GR, et al. EULAR standardised operating procedures for the elaboration, evaluation, dissemination, and implementation of recommendations endorsed by the EULAR standing committees. Ann Rheum Dis 2004;63:1172-6.

19 van der Heijde D, Aletaha D, Carmona L, et al. 2014 Update of the EULAR standardised operating procedures for EULAR-endorsed recommendations. Ann Rheum Dis 2015;74:8-13.

20 Colebatch-Bourn AN, Conaghan PG, Arden NK, et al. Raising the quality of rheumatology management recommendations: lessons from the EULAR process 10 years after provision of standard operating procedures. Rheumatology (Oxford) 2015:54:1392-6.

21 Annemans L, Spaepen E, Gaskin M, et al. Gout in the UK and Germany: prevalence, comorbidities and management in general practice 2000-2005. Ann Rheum Dis 2008;67:960-6.

22 Roddy E, Zhang W, Doherty M. Concordance of the management of chronic gout in a UK primary-care population with the EULAR gout recommendations. Ann Rheum Dis 2007;66:1311-15.

23 Harrold LR, Mazor KM, Negron A, et al. Primary care providers' knowledge, beliefs and treatment practices for gout: results of a physician questionnaire. Rheumatology (Oxford) 2013;52:1623-9.

24 Kuo CF, Grainge MJ, Mallen C, et al. Eligibility for and prescription of urate-lowering treatment in patients with incident gout in England. JAMA 2015;312:2684-6.

25 Spencer K, Carr A, Doherty M. Patient and provider barriers to effective management of gout in general practice: a qualitative study. Ann Rheum Dis 2012:71:1490-5.

26 Reach G. Treatment adherence in patients with gout. Joint Bone Spine 2011;78:456-9.

27 Harrold LR, Andrade SE, Briesacher BA, et al. Adherence with urate-lowering therapies for the treatment of gout. Arthritis Res Ther 2009;11:R46.

28 Rees $F$, Jenkins W, Doherty M. Patients with gout adhere to curative treatment if informed appropriately: proof-of-concept observational study. Ann Rheum Dis 2013;72:826-30.

29 Williams PT. Effects of diet, physical activity and performance, and body weight on incident gout in ostensibly healthy, vigorously active men. Am J Clin Nutr 2008;87:1480-7.

30 Dalbeth $\mathrm{N}$, Chen $\mathrm{P}$, White $\mathrm{M}$, et al. Impact of bariatric surgery on serum urate targets in people with morbid obesity and diabetes: a prospective longitudinal study. Ann Rheum Dis 2014;73:797-802.

31 Zhu Y, Zhang Y, Choi HK. The serum urate-lowering impact of weight loss among men with a high cardiovascular risk profile: the Multiple Risk Factor Intervention Trial. Rheumatology (Oxford) 2010:49:2391-9.

32 Richette $\mathrm{P}$, Poitou $\mathrm{C}$, Manivet $\mathrm{P}$, et al. Weight loss, xanthine oxidase and serum urate levels: a prospective, longitudinal study of obese patients. Arthritis Care Res (Hoboken) 2016;68:1036-42.

33 Chen JH, Wen CP, Wu SB, et al. Attenuating the mortality risk of high serum uric acid: the role of physical activity underused. Ann Rheum Dis 2015;74:2034-42.

34 Roddy E, Choi HK. Epidemiology of gout. Rheum Dis Clin North Am 2014;40:155-75.

35 Bhole $\mathrm{V}$, de Vera $\mathrm{M}$, Rahman MM, et al. Epidemiology of gout in women: fifty-two-year follow-up of a prospective cohort. Arthritis Rheum 2010;62:1069-76

36 Zhang $\mathrm{Y}$, Chen $\mathrm{C}$, Choi $\mathrm{H}$, et al. Purine-rich foods intake and recurrent gout attacks. Ann Rheum Dis 2012;71:1448-53.

37 Zhang $Y$, Woods R, Chaisson CE, et al. Alcohol consumption as a trigger of recurrent gout attacks. Am J Med 2006;119:800.e13-8.

38 Choi HK, Curhan G. Soft drinks, fructose consumption, and the risk of gout in men: prospective cohort study. BMJ 2008;336:309-12.

39 Choi HK, Willett W, Curhan G. Fructose-rich beverages and risk of gout in women JAMA 2010;304:2270-8.
40 Gao X, Qi L, Qiao N, et al. Intake of added sugar and sugar-sweetened drink and serum uric acid concentration in US men and women. Hypertension 2007; 50:306-12

41 Choi JW, Ford ES, Gao X, et al. Sugar-sweetened soft drinks, diet soft drinks, and serum uric acid level: the Third National Health and Nutrition Examination Survey. Arthritis Rheum 2008;59:109-16.

42 Choi HK, Curhan G. Coffee, tea, and caffeine consumption and serum uric acid level: the third national health and nutrition examination survey. Arthritis Rheum 2007:57:816-21.

43 Choi HK, Curhan G. Coffee consumption and risk of incident gout in women: the Nurses' Health Study. Am J Clin Nutr 2010;92:922-7.

44 Choi HK, Willett W, Curhan G. Coffee consumption and risk of incident gout in men: a prospective study. Arthritis Rheum 2007;56:2049-55.

45 Zhang $Y$, Neogi T, Chen $C$, et al. Cherry consumption and decreased risk of recurrent gout attacks. Arthritis Rheum 2012;64:4004-11.

46 Zgaga L, Theodoratou E, Kyle J, et al. The association of dietary intake of purine-rich vegetables, sugar-sweetened beverages and dairy with plasma urate, in a cross-sectional study. PLOS ONE 2012;7:e38123.

47 Dalbeth N, Wong S, Gamble GD, et al. Acute effect of milk on serum urate concentrations: a randomised controlled crossover trial. Ann Rheum Dis 2010;69:1677-82.

48 Dalbeth N, Ames R, Gamble GD, et al. Effects of skim milk powder enriched with glycomacropeptide and G600 milk fat extract on frequency of gout flares: a proof-of-concept randomised controlled trial. Ann Rheum Dis 2012;71:929-34.

49 Holland R, McGill NW. Comprehensive dietary education in treated gout patients does not further improve serum urate. Intern Med J 2015;45:189-94.

50 Moi JH, Sriranganathan MK, Falzon L, et al. Lifestyle interventions for the treatment of gout: a summary of 2 Cochrane systematic reviews. J Rheumatol Supp/ 2014;92:26-32.

51 Krishnan E. Reduced glomerular function and prevalence of gout: NHANES 2009-10. PLOS ONE 2012;7:e50046.

52 Zhu Y, Pandya BJ, Choi HK. Comorbidities of gout and hyperuricemia in the US general population: NHANES 2007-2008. Am J Med 2011;125:679-687.e1.

53 Jalal DI, Chonchol M, Chen W, et al. Uric acid as a target of therapy in CKD. Am J Kidney Dis 2013:61:134-46.

54 Feig DI, Kang DH, Johnson RJ. Uric acid and cardiovascular risk. N Engl J Med 2008;359:1811-21.

55 Liu SC, Xia L, Zhang J, et al. Gout and risk of myocardial infarction: a systematic review and meta-analysis of cohort studies. PLOS ONE 2015:10:e0134088.

56 Clarson LE, Hider SL, Belcher J, et al. Increased risk of vascular disease associated with gout: a retrospective, matched cohort study in the UK clinical practice research datalink. Ann Rheum Dis 2015;74:642-7.

57 Krishnan E, Baker JF, Furst DE, et al. Gout and the risk of acute myocardial infarction. Arthritis Rheum 2006:54:2688-96.

58 Choi HK, Curhan G. Independent impact of gout on mortality and risk for coronary heart disease. Circulation 2007:116:894-900.

59 De Vera MA, Rahman MM, Bhole V, et al. Independent impact of gout on the risk of acute myocardial infarction among elderly women: a population-based study. Ann Rheum Dis 2010;69:1162-4.

60 Baker JF, Schumacher HR, Krishnan E. Serum uric acid level and risk for periphera arterial disease: analysis of data from the multiple risk factor intervention trial. Angiology 2007:58:450-7.

61 Krishnan E. Gout and the risk for incident heart failure and systolic dysfunction. BMJ Open 2012:2:e000282.

62 Seminog 00, Goldacre MJ. Gout as a risk factor for myocardial infarction and stroke in England: evidence from record linkage studies. Rheumatology (Oxford) 2013;52:2251-9.

63 Krishnan E, Akhras KS, Sharma H, et al. Relative and attributable diabetes risk associated with hyperuricemia in US veterans with gout. OJM 2013:106:721-9.

64 Keenan RT, O'Brien WR, Lee KH, et al. Prevalence of contraindications and prescription of pharmacologic therapies for gout. Am J Med 2011;124: 155-63.

65 Terkeltaub RA, Furst DE, Bennett $\mathrm{K}$, et al. High versus low dosing of oral colchicine for early acute gout flare: twenty-four-hour outcome of the first multicenter, randomized, double-blind, placebo-controlled, parallel-group, dose-comparison colchicine study. Arthritis Rheum 2010:62:1060-8.

66 van Durme CM, Wechalekar MD, Buchbinder R, et al. Non-steroidal anti-inflammatory drugs for acute gout. Cochrane Database Syst Rev 2014;(9): CD010120.

67 Li T, Chen SL, Dai Q, et al. Etoricoxib versus indomethacin in the treatment of Chinese patients with acute gouty arthritis: a randomized double-blind trial. Chin Med J 2013:126:1867-71.

68 Schumacher HR, Berger MF, Li-Yu J, et al. Efficacy and tolerability of celecoxib in the treatment of acute gouty arthritis: a randomized controlled trial. J Rheumatol 2012:39:1859-66.

69 Willburger RE, Mysler E, Derbot J, et al. Lumiracoxib $400 \mathrm{mg}$ once daily is comparable to indomethacin $50 \mathrm{mg}$ three times daily for the treatment of acute flares of gout. Rheumatology (Oxford) 2007;46:1126-32. 
70 Rainer $\mathrm{TH}$, Cheng $\mathrm{CH}$, Janssens $\mathrm{HJ}$, et al. Oral prednisolone in the treatment of acute gout: a pragmatic, multicenter, double-blind, randomized trial. Ann Intern Med 2016;164:464-71.

71 Janssens $H J$, Janssen $M$, van de Lisdonk $E H$, et al. Use of oral prednisolone or naproxen for the treatment of gout arthritis: a double-blind, randomised equivalence trial. Lancet 2008;371:1854-60.

72 Man CY, Cheung IT, Cameron PA, et al. Comparison of oral prednisolone/ paracetamol and oral indomethacin/paracetamol combination therapy in the treatment of acute gout-like arthritis: a double-blind, randomized, controlled trial. Ann Emerg Med 2007;49:670-7.

73 Terkeltaub RA, Furst DE, Digiacinto JL, et al. Novel evidence-based colchicine dose-reduction algorithm to predict and prevent colchicine toxicity in the presence of cytochrome P450 3A4/P-glycoprotein inhibitors. Arthritis Rheum 2011;63:2226-37.

74 Richette P, Bardin T. Colchicine for the treatment of gout. Expert Opin Pharmacother 2010;11:2933-8.

75 Wason S, Mount D, Faulkner R. Single-dose, open-label study of the differences in pharmacokinetics of colchicine in subjects with renal impairment, including end-stage renal disease. Clin Drug Investig 2014;34:845-55.

76 Fernández C, Noguera R, González JA, et al. Treatment of acute attacks of gout with a small dose of intraarticular triamcinolone acetonide. J Rheumatol 1999;26:2285-6.

77 Wechalekar MD, Vinik 0, Schlesinger N, et al. Intra-articular glucocorticoids for acute gout. Cochrane Database Syst Rev 2013;(4):CD009920.

78 Martinon F, Pétrilli V, Mayor A, et al. Gout-associated uric acid crystals activate the NALP3 inflammasome. Nature 2006;440:237-41.

79 Schlesinger N, Alten RE, Bardin T, et al. Canakinumab for acute gouty arthritis in patients with limited treatment options: results from two randomised, multicentre, active-controlled, double-blind trials and their initial extensions. Ann Rheum Dis 2012;71:1839-48.

80 So A, De Smedt T, Revaz S, et al. A pilot study of IL-1 inhibition by anakinra in acute gout. Arthritis Res Ther 2007;9:R28.

81 Chen K, Fields T, Mancuso CA, et al. Anakinra's efficacy is variable in refractory gout: report of ten cases. Semin Arthritis Rheum 2010;40:210-14.

82 Ottaviani S, Moltó A, Ea HK, et al. Efficacy of anakinra in gouty arthritis: a retrospective study of 40 cases. Arthritis Res Ther 2013;15:R123.

83 Ghosh P, Cho M, Rawat G, et al. Treatment of acute gouty arthritis in complex hospitalized patients with anakinra. Arthritis Care Res (Hoboken) 2013;65:1381-4.

84 Terkeltaub R, Sundy JS, Schumacher HR, et al. The interleukin 1 inhibitor rilonacept in treatment of chronic gouty arthritis: results of a placebo-controlled, monosequence crossover, non-randomised, single-blind pilot study. Ann Rheum Dis 2009;68:1613-17.

85 Terkeltaub RA, Schumacher HR, Carter JD, et al. Rilonacept in the treatment of acute gouty arthritis: a randomized, controlled clinical trial using indomethacin as the active comparator. Arthritis Res Ther 2013;15:R25.

86 Schlesinger N. Canakinumab in gout. Expert Opin Biol Ther 2012;12:1265-75.

87 Becker MA, MacDonald PA, Hunt BJ, et al. Determinants of the clinical outcomes of gout during the first year of urate-lowering therapy. Nucleosides Nucleotides Nucleic Acids 2008:27:585-91.

88 Wortmann RL, Macdonald PA, Hunt B, et al. Effect of prophylaxis on gout flares after the initiation of urate-lowering therapy: analysis of data from three phase III trials. Clin Ther 2010;32:2386-97.

89 Finkelstein $Y$, Aks SE, Hutson JR, et al. Colchicine poisoning: the dark side of an ancient drug. Clin Toxicol (Phila) 2010;48:407-14.

90 Nidorf SM, Eikelboom JW, Budgeon CA, et al. Low-dose colchicine for secondary prevention of cardiovascular disease. J Am Coll Cardiol 2013;61:404-10.

91 Deftereos S, Giannopoulos G, Raisakis K, et al. Colchicine treatment for the prevention of bare-metal stent restenosis in diabetic patients. J Am Coll Cardiol 2013;61:1679-85.

92 Schlesinger $\mathrm{N}$, Mysler $\mathrm{E}$, Lin HY, et al. Canakinumab reduces the risk of acute gouty arthritis flares during initiation of allopurinol treatment: results of a double-blind, randomised study. Ann Rheum Dis 2011;70:1264-71.

93 Schumacher HR Jr, Sundy JS, Terkeltaub R, et al. Rilonacept (interleukin-1 trap) in the prevention of acute gout flares during initiation of urate-lowering therapy: results of a phase II randomized, double-blind, placebo-controlled trial. Arthritis Rheum 2012;64:876-84.

94 Mitha E, Schumacher HR, Fouche L, et al. Rilonacept for gout flare prevention during initiation of uric acid-lowering therapy: results from the PRESURGE-2 international, phase 3, randomized, placebo-controlled trial. Rheumatology (Oxford) 2013;52:1285-92.

95 Schumacher HR Jr, Evans RR, Saag KG, et al. Rilonacept (interleukin-1 trap) for prevention of gout flares during initiation of uric acid-lowering therapy: results from a phase III randomized, double-blind, placebo-controlled, confirmatory efficacy study. Arthritis Care Res (Hoboken) 2012;64:1462-70.

96 Sundy JS, Schumacher HR, Kivitz A, et al. Rilonacept for gout flare prevention in patients receiving uric acid-lowering therapy: results of RESURGE, a phase III, international safety study. J Rheumatol 2014;41:1703-11.
97 Schumacher HR Jr, Becker MA, Wortmann RL, et al. Effects of febuxostat versus allopurinol and placebo in reducing serum urate in subjects with hyperuricemia and gout: a 28-week, phase III, randomized, double-blind, parallel-group trial. Arthritis Rheum 2008;59:1540-8.

98 Becker MA, Schumacher HR Jr, Wortmann RL, et al. Febuxostat compared with allopurinol in patients with hyperuricemia and gout. N Engl J Med 2005;353:2450-61.

99 Sundy JS, Baraf HS, Yood RA, et al. Efficacy and tolerability of pegloticase for the treatment of chronic gout in patients refractory to conventional treatment: two randomized controlled trials. JAMA 2011;306:711-20.

100 Baraf HS, Becker MA, Gutierrez-Urena SR, et al. Tophus burden reduction with pegloticase: results from phase 3 randomized trials and open-label extension in patients with chronic gout refractory to conventional therapy. Arthritis Res Ther 2013;15:R137.

101 Strand V, Khanna D, Singh JA, et al. Improved health-related quality of life and physical function in patients with refractory chronic gout following treatment with pegloticase: evidence from phase III randomized controlled trials. J Rheumatol 2012;39:1450-7.

102 Richette P. Debulking the urate load to feel better. J Rheumatol 2012;39:1311-13.

103 Scire CA, Manara M, Cimmino MA, et al. Gout impacts on function and health-related quality of life beyond associated risk factors and medical conditions: results from the KING observational study of the Italian Society for Rheumatology (SIR). Arthritis Res Ther 2013;15:R101.

104 Becker MA, Schumacher HR, Benjamin KL, et al. Quality of life and disability in patients with treatment-failure gout. J Rheumatol 2009;36:1041-8.

105 Singh JA, Strand V. Gout is associated with more comorbidities, poorer health-related quality of life and higher healthcare utilisation in US veterans. Ann Rheum Dis 2008;67:1310-16.

106 Chandratre $P$, Roddy E, Clarson L, et al. Health-related quality of life in gout: a systematic review. Rheumatology (Oxford) 2013;52:2031-40.

107 Stack AG, Hanley A, Casserly LF, et al. Independent and conjoint associations of gout and hyperuricaemia with total and cardiovascular mortality. QJM 2013;106:647-58.

108 Bhole V, Krishnan E. Gout and the heart. Rheum Dis Clin North Am 2014;40:125-43.

109 Richette P, Perez-Ruiz F. Serum uric acid and metabolic risk. Curr Med Res Opin 2013;29(Suppl 3):9-15.

110 Krishnan E, Svendsen K, Neaton JD, et al. Long-term cardiovascular mortality among middle-aged men with gout. Arch Intern Med 2008;168: 1104-10.

111 Higgins $\mathrm{P}$, Dawson J, Lees KR, et al. Xanthine oxidase inhibition for the treatment of cardiovascular disease: a systematic review and meta-analysis. Cardiovasc Ther 2012;30:217-26.

112 Agarwal V, Hans N, Messerli FH. Effect of allopurinol on blood pressure: a systematic review and meta-analysis. J Clin Hypertens (Greenwich) 2013; 15:435-42.

113 Goicoechea M, Garcia de Vinuesa S, Verdalles U, et al. Allopurinol and progression of CKD and cardiovascular events: long-term follow-up of a randomized clinical trial. Am J Kidney Dis 2015;65:543-9.

114 Bose B, Badve SV, Hiremath SS, et al. Effects of uric acid-lowering therapy on renal outcomes: a systematic review and meta-analysis. Nephrol Dial Transplant 2014;29:406-13.

115 Kanji T, Gandhi M, Clase CM, et al. Urate lowering therapy to improve renal outcomes in patients with chronic kidney disease: systematic review and meta-analysis. BMC Nephrol 2015;16:58.

116 Sircar D, Chatterjee S, Waikhom R, et al. Efficacy of Febuxostat for slowing the GFR decline in patients with CKD and asymptomatic hyperuricemia: a 6-month, double-blind, randomized, placebo-controlled trial. Am J Kidney Dis 2015;66:945-50.

117 Noman A, Ang DS, Ogston S, et al. Effect of high-dose allopurinol on exercise in patients with chronic stable angina: a randomised, placebo controlled crossover trial. Lancet 2010;375:2161-7.

118 Kelkar A, Kuo A, Frishman WH. Allopurinol as a cardiovascular drug. Cardiol Rev 2011;19:265-71.

119 Thanassoulis G, Brophy JM, Richard H, et al. Gout, allopurinol use, and heart failure outcomes. Arch Intern Med 2010;170:1358-64.

120 Givertz MM, Anstrom KJ, Redfield MM, et al. Effects of xanthine oxidase inhibition in hyperuricemic heart failure patients: the xanthine oxidase inhibition for hyperuricemic heart failure patients (EXACT-HF) study. Circulation 2015;131:1763-71.

121 Grimaldi-Bensouda L, Alpérovitch A, Aubrun E, et al. Impact of allopurinol on risk of myocardial infarction. Ann Rheum Dis 2015;74:836-42.

122 de Abajo FJ, Gil MJ, Rodríguez A, et al. Allopurinol use and risk of non-fatal acute myocardial infarction. Heart 2015;101:679-85.

123 Kok VC, Horng JT, Chang WS, et al. Allopurinol therapy in gout patients does not associate with beneficial cardiovascular outcomes: a population-based matched-cohort study. PLOS ONE 2014;9:e99102. 
124 Saag KG, Whelton A, Becker MA, et al. Impact of febuxostat on renal function in gout subjects with moderate-to-severe renal impairment. Arthritis Rheumatol 2016. [Epub ahead of print 19 Feb 2016]. doi:10.1002/art.39654

125 Wu EQ, Patel PA, Mody RR, et al. Frequency, risk, and cost of gout-related episodes among the elderly: does serum uric acid level matter? J Rheumatol 2009;36:1032-40.

126 Abhishek A, Valdes AM, Zhang W, et al. Serum uric acid \& disease duration associate with frequent gout attacks but are poor at identifying such patients: a case control study. Arthritis Care Res (Hoboken) 2016. [Epub ahead of print 11 Feb 2016]. doi:10.1002/acr.22855

127 Singh JA, Reddy SG, Kundukulam J. Risk factors for gout and prevention: a systematic review of the literature. Curr Opin Rheumatol 2011;23:192-202.

128 Rothenbacher $D$, Primatesta $P$, Ferreira $A$, et al. Frequency and risk factors of gout flares in a large population-based cohort of incident gout. Rheumatology (Oxford) 2011;50:973-81.

129 Yamanaka H. Gout and hyperuricemia in young people. Curr Opin Rheumatol 2011;23:156-60.

130 Taylor TH, Mecchella JN, Larson RJ, et al. Initiation of allopurinol at first medical contact for acute attacks of gout: a randomized clinical trial. Am J Med 2012;125:1126-1134.e7.

131 Hill EM, Sky K, Sit M, et al. Does starting allopurinol prolong acute treated gout? A randomized clinical trial. J Clin Rheumatol 2015;21:120-5.

132 Bardin T. Hyperuricemia starts at 360 micromoles (6 mg/dL). Joint Bone Spine 2015;82:141-3.

133 Pascual E, Sivera F. Time required for disappearance of urate crystals from synovial fluid after successful hypouricaemic treatment relates to the duration of gout. Ann Rheum Dis 2007;66:1056-8.

134 Perez-Ruiz F, Lioté F. Lowering serum uric acid levels: what is the optimal target for improving clinical outcomes in gout? Arthritis Rheum 2007;57:1324-8.

135 Perez-Ruiz F, Calabozo M, Pijoan Jl, et al. Effect of urate-lowering therapy on the velocity of size reduction of tophi in chronic gout. Arthritis Rheum 2002:47:356-60.

136 Chamorro A, Amaro S, Castellanos M, et al. Safety and efficacy of uric acid in patients with acute stroke (URICO-ICTUS): a randomised, double-blind phase $2 \mathrm{~b} / 3$ trial. Lancet Neurol 2014;13:453-60.

137 Peng $F$, Zhang B, Zhong $X$, et al. Serum uric acid levels of patients with multiple sclerosis and other neurological diseases. Mult Scler 2008;14:188-96.

138 Schretlen DJ, Inscore AB, Vannorsdall TD, et al. Serum uric acid and brain ischemia in normal elderly adults. Neurology 2007;69:1418-23.

139 Chen H, Mosley TH, Alonso A, et al. Plasma urate and Parkinson's disease in the Atherosclerosis Risk in Communities (ARIC) study. Am J Epidemiol 2009;169:1064-9.

140 Weisskopf MG, O'Reilly E, Chen $\mathrm{H}$, et al. Plasma urate and risk of Parkinson's disease. Am J Epidemiol 2007;166:561-7.

141 Kim TS, Pae CU, Yoon SJ, et al. Decreased plasma antioxidants in patients with Alzheimer's disease. Int J Geriatr Psychiatry 2006;21:344-8.

142 Abraham A, Drory VE. Influence of serum uric acid levels on prognosis and survival in amyotrophic lateral sclerosis: a meta-analysis. J Neurol 2014;261:1133-8

143 Zandman-Goddard G, Amital H, Shamrayevsky N, et al. Rates of adherence and persistence with allopurinol therapy among gout patients in Israel. Rheumatology (Oxford) 2013;52:1126-31.

144 Solomon DH, Avorn J, Levin R, et al. Uric acid lowering therapy: prescribing patterns in a large cohort of older adults. Ann Rheum Dis 2008;67:609-13.

145 Perez-Ruiz F, Herrero-Beites AM, Carmona L. A two-stage approach to the treatment of hyperuricemia in gout: the "dirty dish" hypothesis. Arthritis Rheum 2011;63:4002-6

146 Meltzer M, Pizzi LT, Jutkowitz E. Payer decision-making with limited comparative and cost effectiveness data: the case of new pharmacological treatments for gout Evid Based Med 2012;17:105-8.

147 Jutkowitz E, Choi HK, Pizzi LT, et al. Cost-effectiveness of allopurinol and febuxostat for the management of gout. Ann Intern Med 2014;161:617-26.

148 Reinders MK, van Roon EN, Jansen TL, et al. Efficacy and tolerability of urate-lowering drugs in gout: a randomised controlled trial of benzbromarone versus probenecid after failure of allopurinol. Ann Rheum Dis 2009;68:51-6.

149 Becker MA, Schumacher HR, Espinoza LR, et al. The urate-lowering efficacy and safety of febuxostat in the treatment of the hyperuricemia of gout: the CONFIRMS trial. Arthritis Res Ther 2010;12:R63.

150 Reinders MK, Haagsma C, Jansen $\mathrm{TL}$, et al. A randomised controlled trial on the efficacy and tolerability with dose escalation of allopurinol $300-600 \mathrm{mg} /$ day versus benzbromarone 100-200 mg/day in patients with gout. Ann Rheum Dis 2009:68:892-7.

151 Becker MA, Schumacher HR Jr, Wortmann RL, et al. Febuxostat, a novel nonpurine selective inhibitor of xanthine oxidase: a twenty-eight-day, multicenter, phase II, randomized, double-blind, placebo-controlled, dose-response clinical trial examining safety and efficacy in patients with gout. Arthritis Rheum 2005:52:916-23.

152 Abeles AM. Febuxostat hypersensitivity. J Rheumatol 2012;39:659.
153 Chohan S. Safety and efficacy of febuxostat treatment in subjects with gout and severe allopurinol adverse reactions. J Rheumatol 2011;38:1957-9.

154 Bardin T, Chalès G, Pascart T, et al. Risk of cutaneous adverse events with febuxostat treatment in patients with skin reaction to allopurinol. A retrospective, hospital-based study of 101 patients with consecutive allopurinol and febuxostat treatment. Joint Bone Spine 2016;83:314-17.

155 Kydd AS, Seth R, Buchbinder R, et al. Uricosuric medications for chronic gout. Cochrane Database Syst Rev 2014;(11):CD010457.

156 Pui K, Gow PJ, Dalbeth N. Efficacy and tolerability of probenecid as urate-lowering therapy in gout; clinical experience in high-prevalence population. J Rheumatol 2013;40:872-6.

157 Reinders MK, van Roon EN, Houtman PM, et al. Biochemical effectiveness of allopurinol and allopurinol-probenecid in previously benzbromarone-treated gout patients. Clin Rheumatol 2007;26:1459-65.

158 Stocker SL, Graham GG, McLachlan AJ, et al. Pharmacokinetic and pharmacodynamic interaction between allopurinol and probenecid in patients with gout. J Rheumatol 2011;38:904-10.

159 Ko TM, Tsai CY, Chen SY, et al. Use of HLA-B ${ }^{\star} 58: 01$ genotyping to prevent allopurinol induced severe cutaneous adverse reactions in Taiwan: national prospective cohort study. BMJ 2015;351:h4848.

160 Perez-Ruiz F, Sundy JS, Miner JN, et al. Lesinurad in combination with allopurinol: results of a phase 2 , randomised, double-blind study in patients with gout with an inadequate response to allopurinol. Ann Rheum Dis 2016;75:1074-80.

161 Halevy S, Ghislain PD, Mockenhaupt M, et al. Allopurinol is the most common cause of Stevens-Johnson syndrome and toxic epidermal necrolysis in Europe and Israel. J Am Acad Dermatol 2008:58:25-32.

162 Kim SC, Newcomb C, Margolis D, et al. Severe cutaneous reactions requiring hospitalization in allopurinol initiators: a population-based cohort study. Arthritis Care Res (Hoboken) 2013;65:578-84.

163 Ramasamy SN, Korb-Wells CS, Kannangara DR, et al. Allopurinol hypersensitivity: a systematic review of all published cases, 1950-2012. Drug Saf 2013;36:953-80.

164 Chung WH, Chang WC, Stocker SL, et al. Insights into the poor prognosis of allopurinol-induced severe cutaneous adverse reactions: the impact of renal insufficiency, high plasma levels of oxypurinol and granulysin. Ann Rheum Dis 2015;74:2157-64.

165 Chao J, Terkeltaub R. A critical reappraisal of allopurinol dosing, safety, and efficacy for hyperuricemia in gout. Curr Rheumatol Rep 2009;11:135-40.

166 Stocker SL, McLachlan AJ, Savic RM, et al. The pharmacokinetics of oxypurinol in people with gout. Br J Clin Pharmacol 2012;74:477-89.

167 Yun J, Mattsson J, Schnyder K, et al. Allopurinol hypersensitivity is primarily mediated by dose-dependent oxypurinol-specific T cell response. Clin Exp Allergy 2013;43:1246-55

168 Dalbeth N, Kumar S, Stamp L, et al. Dose adjustment of allopurinol according to creatinine clearance does not provide adequate control of hyperuricemia in patients with gout. J Rheumatol 2006;33:1646-50.

169 Hande KR, Noone RM, Stone WJ. Severe allopurinol toxicity. Description and guidelines for prevention in patients with renal insufficiency. Am J Med 1984;76:47-56

170 Hira D, Chisaki Y, Noda S, et al. Population pharmacokinetics and therapeutic efficacy of febuxostat in patients with severe renal impairment. Pharmacology 2015;96:90-8.

171 Perez-Ruiz F, Calabozo M, Fernandez-Lopez MJ, et al. Treatment of chronic gout in patients with renal function impairment: an open, randomized, actively controlled study. J Clin Rheumatol 1999;5:49-55.

172 Fujimori S, Ooyama K, Ooyama $\mathrm{H}$, et al. Efficacy of benzbromarone in hyperuricemic patients associated with chronic kidney disease. Nucleosides Nucleotides Nucleic Acids 2011;30:1035-8.

173 Sundy JS, Becker MA, Baraf HS, et al. Reduction of plasma urate levels following treatment with multiple doses of pegloticase (polyethylene glycol-conjugated uricase) in patients with treatment-failure gout: results of a phase II randomized study. Arthritis Rheum 2008;58:2882-91.

174 Lipsky PE, Calabrese LH, Kavanaugh A, et al. Pegloticase immunogenicity: the relationship between efficacy and antibody development in patients treated for refractory chronic gout. Arthritis Res Ther 2014;16:R60.

175 Choi HK, Soriano LC, Zhang Y, et al. Antihypertensive drugs and risk of incident gout among patients with hypertension: population based case-control study. BMJ 2012;344:d8190.

176 Derosa G, Maffioli P, Sahebkar A. Plasma uric acid concentrations are reduced by fenofibrate: a systematic review and meta-analysis of randomized placebo-controlled trials. Pharmacol Res 2015;102:63-70.

177 Ansquer JC, Dalton RN, Caussé E, et al. Effect of fenofibrate on kidney function: a 6-week randomized crossover trial in healthy people. Am J Kidney Dis 2008:51:904-13.

178 Ogata N, Fujimori S, Oka Y, et al. Effects of three strong statins (atorvastatin, pitavastatin, and rosuvastatin) on serum uric acid levels in dyslipidemic patients. Nucleosides Nucleotides Nucleic Acids 2010;29:321-4.

179 Takagi H, Umemoto T. Atorvastatin therapy reduces serum uric acid levels: a meta-analysis of randomized controlled trials. Int J Cardiol 2012;157:255-7. 


\section{Recommendation}

180 Zhu Y, Pandya BJ, Choi HK. Prevalence of gout and hyperuricemia in the US general population: The National Health and Nutrition Examination Survey 2007-2008. Arthritis Rheum 2011;63:3136-41.

181 Crittenden DB, Pillinger MH. New therapies for gout. Annu Rev Med 2013;64:325-37.

182 Bardin T, Richette P. Definition of hyperuricemia and gouty conditions. Curr Opin Rheumatol 2014;26:186-91.

183 Dalbeth N, House ME, Aati O, et al. Urate crystal deposition in asymptomatic hyperuricaemia and symptomatic gout: a dual energy CT study. Ann Rheum Dis 2015;74:908-11.

184 Dalbeth N, Stamp L. Hyperuricaemia and gout: time for a new staging system? Ann Rheum Dis 2014;73:1598-600

185 Khanna D, Fitzgerald JD, Khanna PP, et al. 2012 American College of Rheumatology guidelines for management of gout. Part 1: systematic nonpharmacologic and pharmacologic therapeutic approaches to hyperuricemia. Arthritis Care Res (Hoboken) 2012;64:1431-46.

186 Khanna D, Khanna PP, Fitzgerald JD, et al. 2012 American College of Rheumatology guidelines for management of gout. Part 2: therapy and anti-inflammatory prophylaxis of acute gouty arthritis. Arthritis Care Res (Hoboken) 2012;64:1447-61.
187 Saito Y, Stamp LK, Caudle KE, et al. Clinical Pharmacogenetics Implementation Consortium (CPIC) guidelines for human leukocyte antigen B (HLA-B) genotype and allopurinol dosing: 2015 update. Clin Pharmacol Ther 2015; 99:36-7.

188 Yun J, Marcaida MJ, Eriksson KK, et al. Oxypurinol directly and immediately activates the drug-specific T cells via the preferential use of HLA-B ${ }^{*} 58: 01$ $\mathrm{J}$ Immunol 2014;192:2984-93.

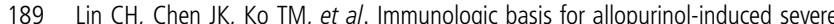
cutaneous adverse reactions: HLA-B*58:01-restricted activation of drug-specific T cells and molecular interaction. J Allergy Clin Immunol 2015;135: 1063-5.e5.

190 Lonjou C, Borot N, Sekula P, et al. A European study of HLA-B in Stevens-Johnson syndrome and toxic epidermal necrolysis related to five high-risk drugs. Pharmacogenet Genomics 2008;18:99-107.

191 Saokaew S, Tassaneeyakul W, Maenthaisong R, et al. Cost-effectiveness analysis of HLA-B*5801 testing in preventing allopurinol-induced SJS/TEN in Thai population. PLOS ONE 2014:9:e94294.

192 Park DJ, Kang JH, Lee JW, et al. Cost-effectiveness analysis of HLA-B5801 genotyping in the treatment of gout patients with chronic renal insufficiency in Korea. Arthritis Care Res (Hoboken) 2015;67:280-7. 